\title{
Contributing Factors to Spatiotemporal Variations of Outgoing Longwave Radiation (OLR) in the Tropics
}

\author{
FAIZ R. FAJARY \\ Department of Geophysics, Kyoto University, Kyoto, Japan, and Atmospheric Sciences Research Group, Institut Teknologi \\ Bandung, Bandung, Indonesia \\ TRI W. HADI \\ Atmospheric Sciences Research Group, Institut Teknologi Bandung, Bandung, Indonesia \\ SHIGEO YODEN \\ Department of Geophysics, Kyoto University, Kyoto, Japan
}

(Manuscript received 30 May 2018, in final form 25 April 2019)

\begin{abstract}
Factors governing spatiotemporal variations of the daily outgoing longwave radiation (OLR) are studied using 35-yr (1979-2013) data records by employing multiple linear regression, wavelet transforms, and bandpass filtering methods. From the regression coefficients of nine predictors and the explained variances, we found that the largest contributions to OLR variability are associated with the Madden-Julian oscillation and El Niño-Southern Oscillation (ENSO). The ENSO signatures on OLR show dipole patterns over the Maritime Continent (MC) and Pacific regions with an extension to the Atlantic. Subsequently, the third significant contribution of the Indian Ocean dipole is confined to the Indian Ocean and Africa. Then, the solar cycle and stratospheric aerosols show mainly negative correlations, while a positive linear trend is observed mainly in the Northern Hemisphere. Lastly, factors associated with the stratospheric quasi-biennial oscillation (QBO) are the least significant contributor to OLR. In terms of oscillatory signals, time-longitude variations of the annual cycle (AC) show pairs of contrasting phases that characterize monsoon systems, in which the MC and Pacific regions are found to be in the same phase group. The most consistent AC signals are found to correspond with North and South American monsoons that respectively exhibit weakening and strengthening trends. Wavelet spectra and filtered OLR signals in intraseasonal oscillation, QBO, and ENSO frequency bands show an interdependent relationship that largely varies with time scale and longitudes.
\end{abstract}

\section{Introduction}

Outgoing longwave radiation (OLR) data have long been used as a proxy for convective cloud activity, with low (high) anomalies indicating enhanced (suppressed) convection. Many scientific papers have explored the versatility of OLR datasets to study convection (e.g., Chu and Wang 1997; Wheeler and Kiladis 1999; Wheeler and Hendon 2004). The National Oceanic and Atmospheric Administration (NOAA) OLR product (Liebmann and Smith 1996) used in this study has its own weakness and strength. The NOAA OLR dataset is derived from narrowband satellite measurements in the infrared window

\footnotetext{
Corresponding author: Shigeo Yoden, yoden@kugi.kyoto-u. ac.jp
}

region. Furthermore, changes in instrument characteristics (e.g., spectral bandpass) and satellite equator crossing times (ECT) throughout the record add considerable uncertainty that is difficult to quantify (Gruber and Krueger 1984). However, it does provide global coverage and relatively continuous observations from 1979 to the present. These features make it one of the few sources of satellite data that can be used for studies of low-frequency climate variability and are likely adequate for studying large-amplitude variations in OLR [e.g., intraseasonal oscillation (ISO), annual cycle (AC), and El NiñoSouthern Oscillation (ENSO)].

Several studies have focused on the spectral properties of clear-sky OLR in relation to changes in greenhouse gas (GHG) concentrations (e.g., Gastineau et al. 2014). Chu and Wang (1997) examined the use of OLR records for 
analyzing long-term changes in tropical convection in the western Pacific and Indian Ocean regions. It is, thus, of interest to extend their study using longer data records with more global coverage. Nevertheless, attributing climate change to OLR variations is complicated. Chu and Wang (1997) pointed out regional and seasonal variations in linear OLR trends, indicating contributions of various factors in OLR variations.

Many studies have shown that OLR variations over the tropics are affected by atmospheric phenomena at different temporal and spatial scales. At synoptic, intraseasonal, and seasonal time scales, OLR variations are affected by equatorial waves (Wheeler and Kiladis 1999), the Madden-Julian oscillation (MJO) (Wheeler and Hendon 2004), and monsoons (Meehl 1987), whereas other phenomena, such as the stratospheric quasibiennial oscillation (QBO) (Collimore et al. 2003), Indian Ocean dipole (IOD) (Saji and Yamagata 2003), ENSO (Wang et al. 1999), and the solar cycle (SC) (Xiao et al.2016), appear to come into play at longer time scales. It is well known that during a single El Niño (La Niña) event, large negative (positive) OLR anomalies are observed in the equatorial central Pacific (e.g., Wang et al. 1999). In addition, more recent studies revealed that interphenomenon modulations, such as stratospheric QBO modulation of the MJO (Yoo and Son 2016; Nishimoto and Yoden 2017; Son et al. 2017), also contribute significantly to OLR variations. Therefore, it is desirable to conduct concurrent analyses of OLR variability across multiple scales using suitable methods.

Multiple linear regression (MLR) is a statistical method that has often been used to analyze multiple variability in atmospheric variables in response to external forcings. Crooks and Gray (2005) used MLR to study the influence of the QBO, ENSO, North Atlantic Oscillation (NAO), SC, and volcanic eruptions (VE) on the zonal-mean zonal wind and temperature with 40-yr European Centre for Medium-Range Weather Forecasts (ECMWF) Re-Analysis (ERA-40) data. Hood et al. (2013) analyzed global sea level pressure (SLP) and sea surface temperature (SST) responses to ENSO, SC, VE, and a linear trend (LT) in the Northern Hemisphere winter over the period from 1880 to 2009. Mitchell et al. (2015) also used MLR to study the contributions of QBO, ENSO, SC, and VE on the corresponding variations of the zonal-mean zonal wind and temperature in the troposphere and stratosphere and compared the results for nine different reanalysis datasets. Cai et al. (2011) applied regression and partial regression methods to examine the OLR anomaly patterns associated with ENSO and IOD during austral winter [June-August (JJA)] and spring [September-November (SON)] in the tropics from Africa to eastern Pacific. By extending the domain, we employ regression methods to investigate the spatial pattern of OLR response to some external forcings.

MLR is useful for analyzing multiple factors that contribute to the variability in any data. This technique, as the first attempt, uses predefined contributing factors based on previous experiments. Although there are limitations to this technique, such as an assumption of stationary correlations between variables, the technique has been usefully employed to investigate the variability in various atmospheric datasets (e.g., Crooks and Gray 2005; Cai et al. 2011; Hood et al. 2013; Mitchell et al. 2015). For the next effort, wavelet transforms, which are suitable for nonstationary time series, are employed. In earlier works, Torrence and Webster (1999) used wavelet analysis to show that the ENSO and Indian monsoon have undergone significant interdecadal changes in variance and coherence. Ma et al. (2010) applied wavelet transforms to analyze QBO signal in monthly OLR data over a limited area of the equatorial region $\left(160^{\circ} \mathrm{E}-160^{\circ} \mathrm{W}\right)$, and showed that the QBO signal has remarkable temporal variability in its amplitude and phase. Lim et al. (2013) used wavelet transforms to study the relative contributions of annual and semiannual cycles in daily OLR variations over three regions in peninsular Malaysia. Modulation at shorter time scales has been studied by Vitorino et al. (2006), who performed wavelet analysis on OLR and tropospheric relative vorticity to study the seasonality of submonthly and intraseasonal signals in the tropics, especially over the South American region. In addition, Cao et al. (2012) used wavelet analysis to study the convectively coupled equatorial waves and ISO.

In this research, we aim to quantify gross contributions of various phenomena that could modulate OLR variations, namely ISO, QBO, IOD, ENSO, SC, VE, and secular LT in global OLR data using MLR analysis. We also apply wavelet transforms to analyze OLR variability in the tropics, focusing on four components of oscillations, namely the ISO, AC, QBO, and ENSO. In addition, other complementary techniques involving Fourier transforms for time series data filtering are also employed in the analyses.

This paper is composed of five sections, with data and methods briefly described in the next section. Section 3 presents results, which are broken down into three subsections highlighting outputs from MLR, wavelet analysis, and bandpass filtering. Section 4 presents a discussion of the results, while conclusions are presented in the final section 5 .

\section{Data and methods}

\section{a. Data}

This study primarily utilizes daily averaged OLR from the twice-daily dataset for the period from 1979 to 2013 
(Liebmann and Smith 1996) provided by the NOAA/ Earth System Research Laboratory (ESRL). The OLR data have a spatial resolution of $2.5^{\circ}$, and are freely downloadable from http://www.esrl.noaa.gov/psd/. Duvel et al. (2001) noted that there is a problem with the data in September 1994. Therefore, before further analyses, quality control of the data was conducted by analyzing outliers from the global area average of daily OLR for one specific month. An outlier is defined as a value located outside the threshold known as the upper and lower outer fence [Eq. (3.11) in Wilks 2011]. This procedure was then repeated for the other 11 months. The gridded OLR on the date of the outlier is considered as error, and a simple temporal linear interpolation was employed to replace the erroneous values in each grid. In this case, three periods in the OLR (less than $0.2 \%$ of the analysis period) are considered as errors, namely 21 May 1982, 19-20 December 1982, and 16 September3 October 1994.

In addition to OLR, we also use six additional datasets described below.

\section{1) OLR-BASED MJO INDEX (OMI)}

The OLR-based MJO index (OMI) is assumed to represent ISO associated with the MJO in OLR variability. The index consists of the first two principal components, OMIPC1 and OMIPC2, as shown in Fig. 1a, which are derived by projecting 20-96-day filtered OLR in the equatorial regions between $20^{\circ} \mathrm{S}$ and $20^{\circ} \mathrm{N}$, including all eastward and westward wavenumbers onto the daily spatial empirical orthogonal function (EOF) patterns of 30-96-day eastward-filtered OLR (Kiladis et al. 2014). The daily OMI amplitude is defined by $\sqrt{\mathrm{OMIPC}^{2}+\mathrm{OMIPC}^{2}}$. These datasets are available for download at https://www.esrl.noaa.gov/ psd/mjo/mjoindex/ for the period of 1979-2013.

\section{2) QBO INDEX}

In contrast to the MJO, which does not exist all the time and has large amplitude fluctuation, the stratospheric QBO is characterized by a much more regular oscillation. This characteristic of the QBO can be represented by the first two PCs derived from the EOF analysis of the covariance matrix of daily zonal-mean zonal wind anomaly over the equatorial belt $\left(10^{\circ} \mathrm{S}-10^{\circ} \mathrm{N}\right)$ at $10,20,30,50$, and $70 \mathrm{hPa}$ (Wallace et al. 1993). These two PCs show a roughly $\pi / 2$ out-of-phase relationship, similar to a harmonic oscillator. Here, we use rotated [see e.g., Wilks (2011) for a detailed explanation of eigenvector rotation] QBOPC1 and QBOPC2 as the QBO index, instead of amplitude and phase. Figure $1 \mathrm{~b}$ shows daily rotated QBOPC1 (black) and QBOPC2 (red) for a phase angle $\left(\theta_{R}\right)$ equal to $40^{\circ}$, with which the regression coefficients

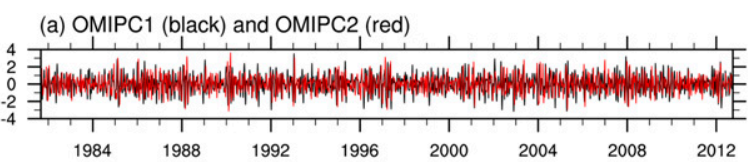

(b) QBOPC1 (black) and QBOPC2 (red) rotated with $\theta_{R}=40^{\circ}$

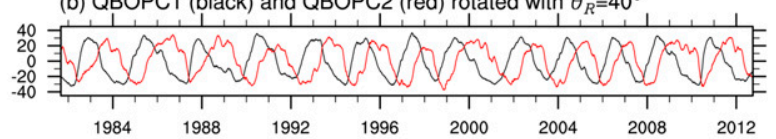

(c) DMI (Dipole Mode Index)
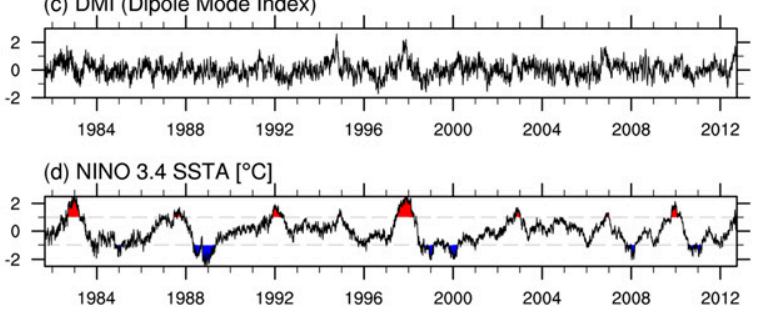

(e) TSI (Total Solar Irradiance) $\left[\mathrm{Wm}^{-2}\right]$
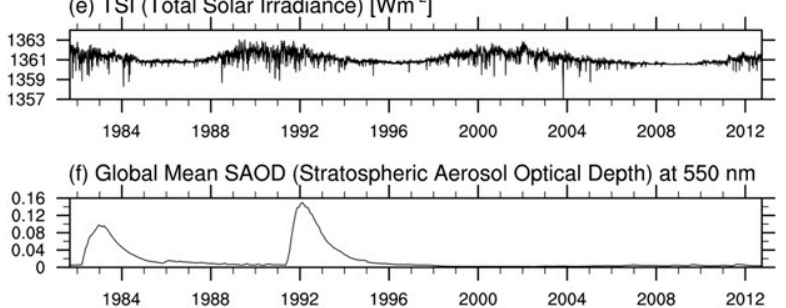

(g) LT (Linear Trend)

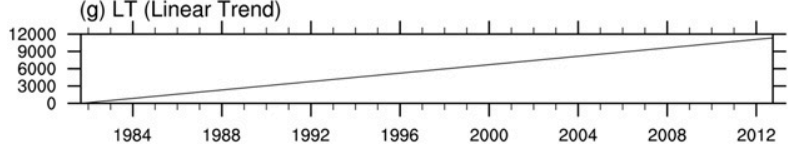

FIG. 1. Time series of daily (a) OMIPC1 (black) and OMIPC2 (red), (b) QBOPC1 (black) and QBOPC2 (red) rotated with $\theta_{R}=$ $40^{\circ}$ (see text for explanation), (c) DMI, (d) Niño-3.4 SSTA, (e) TSI, (f) global mean SAOD at $550 \mathrm{~nm}$, and (g) LT. All time series are from 1 Sep 1981 until 30 Sep 2012. Dashed lines in (d) show thresholds separating El Niño (red) and La Niña (blue) events.

are maximized. It should be noted that before calculating the two PCs, the zonal-mean zonal wind is deseasonalized at each level by subtracting the first harmonics of annual cycle at each grid, and the results are averaged over $10^{\circ} \mathrm{S}-$ $10^{\circ} \mathrm{N}$. The daily zonal wind data are provided by ECMWF as a global interim reanalysis (ERA-Interim; Dee et al. 2011), available at http://apps.ecmwf.int/datasets/data/ interim-full-daily/.

\section{3) DIPOLE MODE INDEX}

Intensity of IOD is represented by the dipole mode index (DMI), which is an anomalous SST gradient between the western equatorial Indian Ocean $\left(10^{\circ} \mathrm{S}-10^{\circ} \mathrm{N}\right.$, $\left.50^{\circ}-70^{\circ} \mathrm{E}\right)$ and the southeastern equatorial Indian Ocean $\left(10^{\circ} \mathrm{S}-0^{\circ}, 90^{\circ}-110^{\circ} \mathrm{E}\right)$. Positive (negative) DMI denotes positive (negative) IOD. Daily DMI is calculated from the NOAA Optimum Interpolation (OI) SST V2 High Resolution Dataset (Reynolds et al. 2007), which is 
available from 1 September 1981 on a $0.25^{\circ}$ grid and can be downloaded from http://www.esrl.noaa.gov/psd/, as shown in Fig. 1c.

\section{4) NiÑO-3.4 SEA SURFACE TEMPERATURE ANOMALY}

The Niño-3.4 sea surface temperature anomaly (SSTA) is an index obtained as an area-averaged daily SST anomaly over the Niño-3.4 region $\left(5^{\circ} \mathrm{S}-5^{\circ} \mathrm{N}, 170^{\circ}-120^{\circ} \mathrm{W}\right)$. The SST data are derived from the NOAA OI SST V2 High Resolution Dataset (Reynolds et al. 2007), also used in calculating DMI. The corresponding time series of the Niño-3.4 SSTA is shown in Fig. 1d, where dashed lines are indicative of thresholds $\left( \pm 1^{\circ} \mathrm{C}\right)$ separating El Niño (red) and La Niña (blue) events.

\section{5) TOTAL SOLAR IRRADIANCE}

Daily total solar irradiance (TSI) data are directly obtained from phase 6 of the Coupled Model Intercomparison Project (CMIP6) web page about the solar forcing at http://solarisheppa.geomar.de/solarisheppa/ cmip6 (Matthes et al. 2017). The time series is shown in Fig. 1e and used to represent 11-yr SC variations. Note that this dataset was reconstructed at 1 astronomical unit $(\mathrm{au} ; 1 \mathrm{au}=149597870700 \mathrm{~m})$.

\section{6) Global MEAN STRATOSPHERIC AEROSOL} OPTICAL DEPTH

Monthly stratospheric aerosol optical depth (SAOD) data through September 2012 can be downloaded from https://data.giss.nasa.gov/modelforce/strataer/ (Sato et al. 1993). Here, SAOD at $550 \mathrm{~nm}$ is used as an index to represent stratospheric variation of aerosols due to large VEs. In this case, the monthly data are upsampled to daily resolution by applying linear interpolation, as shown in Fig. 1f. Two large variations of SAOD are due to the major eruptions of Mount El Chichón in 1983 and Mount Pinatubo in 1991.

\section{b. Methods}

\section{1) Multiple LiNEAR REGRESSION}

In this work, factors contributing to global OLR variability are first investigated by MLR analysis as described in Wilks (2011) and Mitchell et al. (2015). The zero-lagged MLR equation can be expressed as

$$
\operatorname{OLR}(\lambda, \phi, t)=\beta_{0}(\lambda, \phi)+\sum_{i=1}^{9} \beta_{i}(\lambda, \phi) X_{i}(t)+\varepsilon(\lambda, \phi, t),
$$

where $\beta_{0}(\lambda, \phi)$ is the regression constant, $\beta_{i}(i=1,2, \ldots, 9)$ are regression coefficients, and $\varepsilon(\lambda, \phi, t)$ designates the residuals. Note that the predictand (OLR) is a function of longitude $(\lambda)$, latitude $(\phi)$, and time $(t)$, while predictors are the previously mentioned nine indices (shown in Fig. 1), namely OMIPC1, OMIPC2, rotated QBOPC1 $\left(\theta_{R}\right)$ and QBOPC2 $\left(\theta_{R}\right)$ with a rotation angle $\left(\theta_{R}\right)$, DMI, Niño-3.4 SSTA, TSI, SAOD, and LT, at daily time resolution, corresponding to $X_{i}(t), i=1,2, \ldots, 9$ in Eq. (1) for each grid.

Prior to the application of MLR, the predictand is first deseasonalized by removing the first three harmonics of the seasonal cycle for the period from 1979-2013. However, the time series of DMI and Niño-3.4 SSTA begins on 1 September 1981, and SAOD ends on 30 September 2012. This defines the period of MLR analysis as 11353 samples over $30 \mathrm{yr}$. In addition, before the MLR is performed, anomalies of each predictor are calculated by removing the time mean value from the time series over the period of analysis and normalizing against its standard deviation. Following Mitchell et al. (2015), for presentation purposes, the resulting regression coefficients are rescaled by multiplicative factors to give a more meaningful estimate. For the 11-yr $\mathrm{SC}$, the coefficients have been multiplied by the maximum peak-to-trough values of the TSI index to obtain an estimate of the maximum likely response to variations in the sun's output; they therefore represent a "solar maximum minus solar minimum" difference. For the volcanic results, the regression coefficients have been multiplied by the difference between the SAOD at the peak of the Pinatubo eruption and the year (365 days) preceding the eruption; they therefore provide an estimate of the response to a Pinatubo-scale eruption. Similarly, the MJO, QBO, IOD, and ENSO regression coefficients have been multiplied by the difference between the maximum and minimum values of OMIPC1 and OMIPC2, QBOPC1 and QBOPC2, DMI, and Niño-3.4 SSTA, and thus represent an estimate of the maximum likely MJO, QBO-west minus QBO-east, IOD+ minus IOD-, and El Niño minus La Niña signals, respectively. For the trend, the regression coefficients are multiplied by the maximum minus minimum values to estimate the magnitude of the trend in the OLR data. The multiplicative factor for $\beta_{0}$ is 1 . In addition, the mean absolute value $[|\bar{\varepsilon}(\lambda, \phi)|]$ of the residuals $\varepsilon(\lambda, \phi, t)$ is calculated.

Moreover, statistical significance of determined parameters is also examined using a two-tailed Student's $t$ test. When calculating the statistical significance, the effective sample size $\left[N_{\text {eff }}(\lambda, \phi)=N\left(1-r_{1} r_{2}\right) /\left(1+r_{1} r_{2}\right)\right]$ is used for $N$ observations ( $N=11353$ days), where $r_{1}$ is the lag-one autocorrelation of the predictand at each grid point, and $r_{2}$ is the lag-one autocorrelation of the predictor (Bretherton et al. 1999). 
In this study, MLR analysis is conducted for several QBO PCs $\left(\theta_{R}\right)$ by rotating $\theta_{R}$ every $10^{\circ}$ from $\theta_{R}=0^{\circ}$ to $\theta_{R}=80^{\circ}$. One $\theta_{R}$ is determined with the value that gives the maximum or absolute minimum of regression coefficients of two PCs $\left(\theta_{R}\right)$ over the tropical belt (latitude $\left.< \pm 30^{\circ}\right)$. In the MLR results for the whole period, $\theta_{R}=$ $40^{\circ}$. It should be noted that the inherent magnitude of AC is not analyzed in MLR, but its contribution is discussed in the wavelet and bandpass filtering analyses.

\section{2) WAVELET ANALYSES}

In this study, wavelet analyses are employed to assess the contributions of four atmospheric oscillations, namely the ISO, AC, QBO, and ENSO, on global OLR variability. For a given time series data $x_{n}, n=0, \ldots$, $N-1$, with equal time spacing $\delta t$, the wavelet transform is determined by

$$
W_{n}(s)=\sum_{n^{\prime}=0}^{N-1} x_{n^{\prime}} \psi^{*}\left[\frac{\left(n^{\prime}-n\right) \delta t}{s}\right],
$$

where the asterisk indicates the complex conjugate. Equation (2) expresses the convolution of $x_{n}$ on that normalized wavelet function $\psi(\eta)$ that depends on a nondimensional "time" parameter $\eta$, localized in both time and frequency space; with zero mean, it is a scaled and translated version of a mother wavelet $\psi_{0}$. In this study, we use the Morlet wavelet, defined as

$$
\psi_{0}(\eta)=\pi^{-1 / 4} e^{i \omega_{0} \eta} e^{-\eta^{2} / 2},
$$

as the complex mother wavelet that is considered suitable for capturing oscillatory behavior. The described wavelet transforms are implemented using the codes provided by Torrence and Compo (1998), which are available online at http://paos.colorado.edu/research/ wavelets/. Normalization of the wavelet function ensures that the wavelet transforms at each scale $s$ are directly comparable to each other and to the transforms of other time series. Moreover, for Morlet analysis with $\omega_{0}=6$, the relation between Fourier period $p$ and wavelet scales $s$ is $p=1.03 s$, indicating that the Fourier period and wavelet scale are nearly identical (Torrence and Compo 1998). Thus, $\omega_{0}$ is the nondimensional frequency, taken to be 6 to satisfy the admissibility condition (Farge 1992).

From Eq. (2), the wavelet power spectrum or spectrogram is defined by $\left|W_{n}(s)\right|^{2}$. In addition, the global wavelet spectrum (GWS) is obtained by time-averaging the wavelet spectrum over all the local wavelet spectra. Furthermore, scale-averaging across a certain Fourier frequency band is used to identify relative signal strength with time.

\section{3) BANDPASS FILTERING}

For comparison with the wavelet transforms, we additionally use a bandpass filter to analyze oscillatory signals of ISO, AC, QBO, and ENSO time scales. The spectrum of an ideal filter should have zero amplitude over unwanted frequencies and unity over those of interest. Here, a sixth-order Butterworth filter is applied to the normalized daily OLR averaged over $15^{\circ} \mathrm{S}-15^{\circ} \mathrm{N}$ in each longitudinal grid for a period of 35 years (19792013). The selection of latitudinal domain is arbitrary. However, by averaging over different latitudes of $10^{\circ} \mathrm{S}-$ $10^{\circ} \mathrm{N}$ or $20^{\circ} \mathrm{S}-20^{\circ} \mathrm{N}$, the result is not sensitive to the parameter (not shown). The amplitude spectrum of the analog Butterworth bandpass filter is defined by

$$
\left|G_{b}(\omega)\right|^{2}=\frac{1}{1+\left(\frac{|\omega|-\omega_{b}}{\omega_{c}}\right)^{2 n}},
$$

where $\omega_{b}$ is the center of the pass band, $\omega_{c}$ is the pass band half-width, and $n$ is the order of the filter that determines the level of sharpness of the frequency response (Gubbins 2004). The zero-phase filter, which does not change the phase of the original time sequence, is performed in this study. The filtering procedure involves Fourier transformation of the analyzed time sequences multiplied by the frequency response of the filter $\left[\left|G_{b}(\omega)\right|^{2}\right]$. Then, inverse Fourier transformation was performed to render the filtered signal in the time domain. In this case, $n=6$ is selected to minimize overlaps in the four analyzed frequency bands.

\section{Results}

\section{a. MLR coefficients and major contributing factors to $O L R$ variability}

Spatial distributions of regression coefficients from the MLR analyses are shown in Figs. 2b-j. Note that the unit of these figures is $\mathrm{W} \mathrm{m}^{-2}$ per the standard deviation multiplied by constants [described in section $2 b(1)$ ]. The regression constant $\beta_{0}$ is shown in Fig. 2a. In Figs. $2 \mathrm{a}-\mathrm{j}$, blue (red) shadings indicate negative (positive) responses, while hatched regions indicate those with less than a $95 \%$ statistical significance level. In addition, Figs. $2 \mathrm{k}$ and $2 \mathrm{l}$ show the time averages of absolute residuals and standard deviation of residuals, respectively, with the unit of $\mathrm{W} \mathrm{m}^{-2}$.

In general, Figs. 2b-j, respectively, show the relative contributions of OMIPC1, OMIPC2, QBOPC1, QBOPC2, IOD, ENSO, SC, VE, and LT, to the OLR variability in the tropics and extratropics. It can be seen that ISO, represented by the regression coefficients of OMIPC1 (Fig. 2b) and OMIPC2 (Fig. 2c), has the largest influence 
(a) Betao

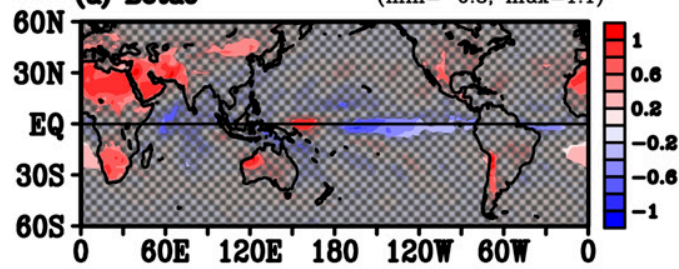

(c) OMIIPC2

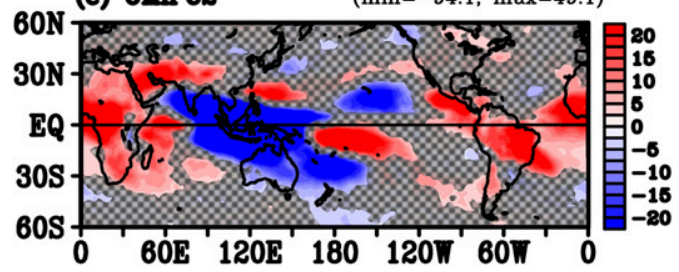

(e) QBOPC2 $\left(\theta_{2}=40^{\circ}\right) \quad(\min =-7.8, \max =10.5)$

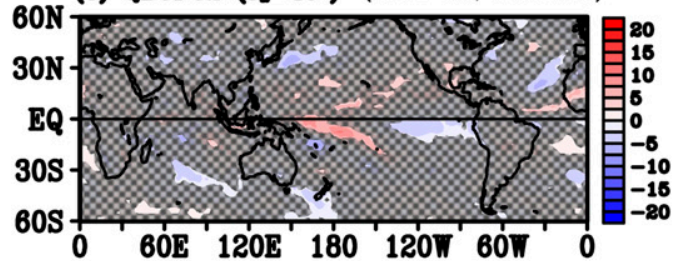

(c) smio 3.4 ssTA $(\min =-89.8, \max =67.7)$
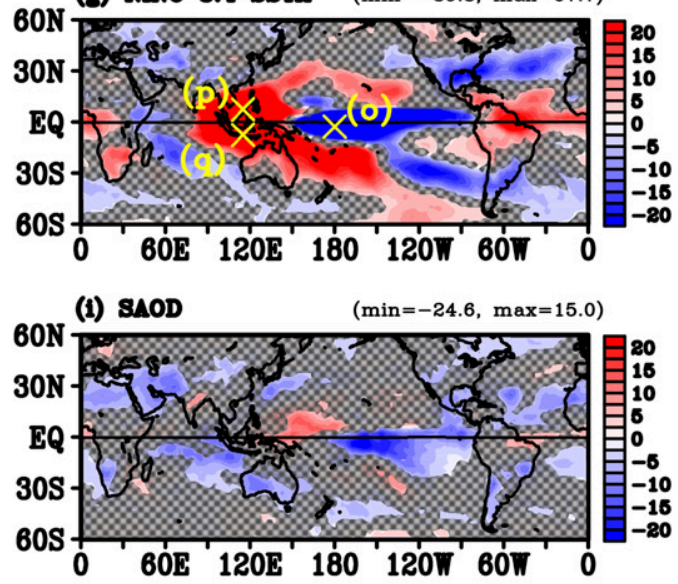

(k) $\Delta$ ve. of fresidual $\quad(\min =4.5, \max =35.3)$

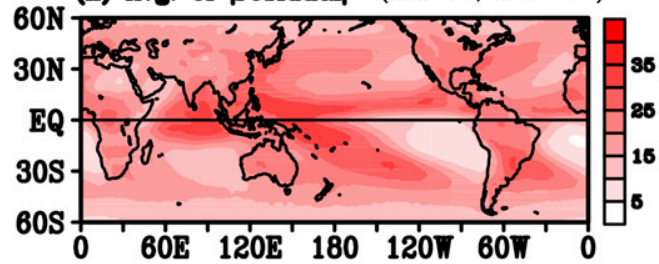

(b) OMIPC1

$(\min =-116.7, \max =69.5)$

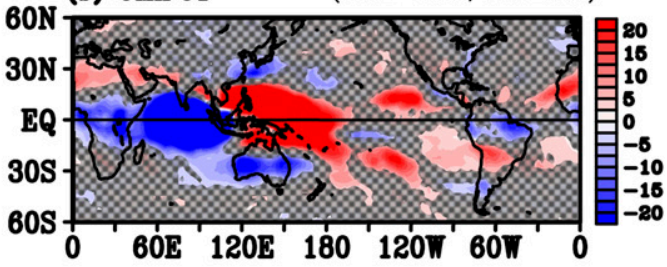

(d) QBOPC1 $\left(\theta_{\mathrm{L}}=40^{\circ}\right) \quad(\min =-8.9, \max =8.2)$

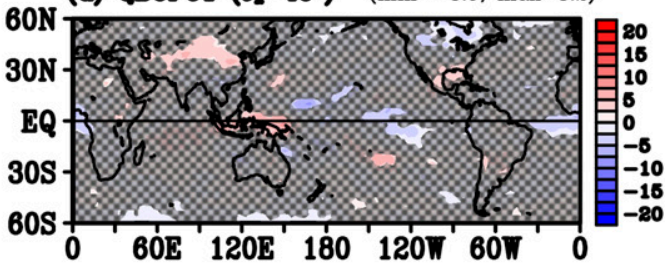

(I) DMI

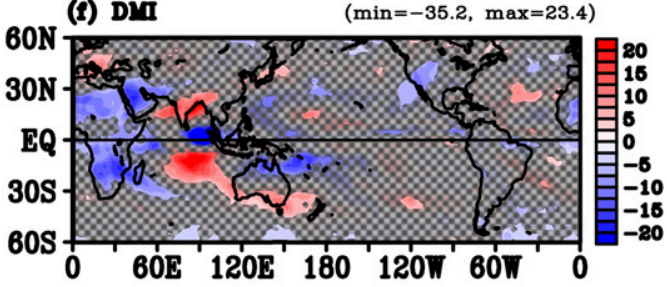

(h) TSI

$(\min =-22.8, \max =17.7)$
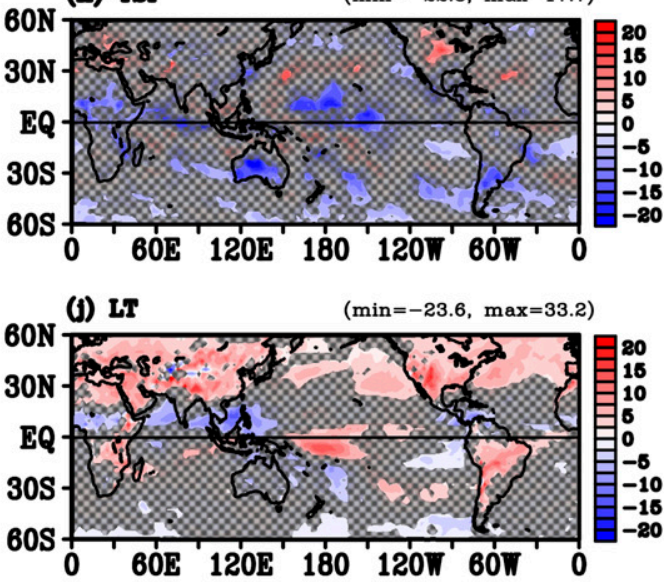

(1) Std. of residual $\quad(\min =6.6, \max =42.1)$

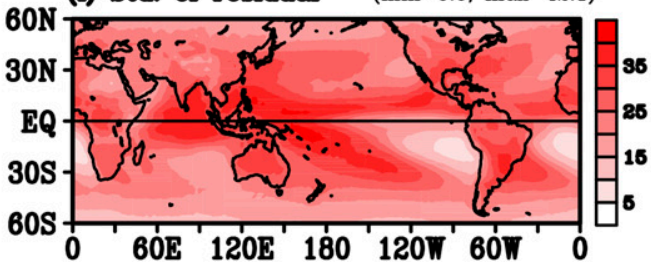

FIG. 2. Spatial distribution of (a) regression constant $\left(\beta_{0}\right)$ and (b) $-(\mathrm{j})$ regression coefficients from MLR analyses of OLR data respective to nine predictors [i.e., OMIPC1, OMIPC2, QBOPC1 $\left(\theta_{R}=40^{\circ}\right)$, QBOPC2 $\left(\theta_{R}=40^{\circ}\right)$, DMI, Niño-3.4 SSTA, TSI, SAOD, and LT]; (k),(l) averages of absolute and standard deviations of the residuals. Hatched regions indicate statistical insignificance (confidence level lower than $95 \%$ ). The units for (a), (k), and (l) are $\mathrm{W} \mathrm{m}^{-2}$ and for (b)-(j) are $\mathrm{W} \mathrm{m}^{-2}$ per standard deviation multiplied by constants (see text for further explanation). Minimum and maximum values of each plot are given at the top-right corner. Three yellow crosses in (g) represent points of minimum $\left[(\mathrm{o}) \lambda=180^{\circ}, \phi=-2.5^{\circ} \mathrm{S}\right]$ and maximum $\left[(\mathrm{p}) \lambda=115^{\circ} \mathrm{E}, \phi=7.5^{\circ} \mathrm{N}\right]$ values of regression coefficients and an additional point over Indonesia $\left[(\mathrm{q}) \lambda=115^{\circ} \mathrm{E}, \phi=-7.5^{\circ} \mathrm{S}\right.$, which are further analyzed in Fig. 4. 
on OLR over the tropics, particularly in the Eastern Hemisphere with an eastward propagating characteristics. ENSO (Fig. 2g) also has a large influence on OLR, with El Niño patterns in the tropics, namely a negative OLR anomaly (enhanced convection) over the Pacific Ocean and a positive OLR anomaly (suppressed convection) over the Maritime Continent (MC).

The responses of large-scale convective activity diagnosed by OLR on predictors can be further described as follows:

- Statistically significant OMIPC1 and OMIPC2 coefficients (Figs. 2b,c) appear mainly over the tropical latitudes between $30^{\circ} \mathrm{S}$ and $30^{\circ} \mathrm{N}$. In addition, the tropical Eastern Hemisphere shows broader influence of the ISO than the tropical Western Hemisphere. An alternating positive and negative pattern along the longitudes appears to represent the modulations of convective signals associated with large ISO events, with the patterns of OMIPC1 influence lead OMIPC2 influence by around $1 / 4$ cycle, which is consistent with Wheeler and Hendon (2004). In addition, the ISO influence also extends to the extratropical regions.

- Significant coefficients for QBOPC1 $\left(\theta_{R}=40^{\circ}\right)$ (Fig. 2d) and QBOPC2 $\left(\theta_{R}=40^{\circ}\right)$ (Fig. 2e) of the QBO indices are rather limited, indicating little linear association, although the largest responses are found along the equator over the MC, Pacific, and Atlantic.

- The influence of DMI on OLR exhibits a dipole pattern over Indian Ocean (Fig. 2f); positive OLR anomalies (suppressed convection) are over the eastern part of Indian Ocean south of the equator, and negative OLR anomalies (enhanced convection) are over the western Indian Ocean. This pattern is similar to the positive IOD pattern. Broader remote influence of DMI is observed over the Eastern Hemisphere compared to the Western Hemisphere. Significant negative responses of OLR to DMI are observed over Africa and western Asia, and the South Pacific convergence zone (SPCZ). Significant positive responses are also observed in some limited areas in India and southeastern Australia. DMI has opposite responses between northern and southern Australia.

- ENSO signatures in OLR data (Fig. 2g) show high statistical significance in the tropics, which is consistent with strong contrasts of the sea surface temperature (e.g., Hood et al. 2013). However, Fig. 2g indicates not only the direct response of ENSO over the tropics, but also the remote influence of the ENSO signal, which extends to the extratropics with positive responses over South Africa, the western South Pacific, and the North Pacific Ocean, while negative responses prevail over the south Indian Ocean, the eastern South Pacific to South
America, and North America to the North Atlantic Ocean.

- From the coefficients of TSI (Fig. 2h), it can be observed that SC has global influence on OLR, with mostly negative correlation (enhanced convection or increased cloud fraction). This is a rather intriguing result given that recent investigations show no conclusive evidence on the correlation between TSI and cloudiness (e.g., Laken and Čalogović 2011). Owing to limited data, we refrain from further investigation of such correlation in this work. However, as noted in Gray et al. (2010), there are two possible mechanisms for how solar variations influence climate, "top-down" and "bottom-up" mechanisms. The first mechanism explains that energy from the different parts of the solar spectrum is absorbed at different heights in the atmosphere, whereby TSI can impact the surface directly. In the second mechanism, the TSI affects solar absorption over the subtropical ocean, which increases evaporation. The increased moisture converges to the tropics and then intensifies convective activities and associated upward vertical motions. More active convection corresponds to lower OLR values.

- The coefficients of SAOD (Fig. 2i) indicate that VE is in general negatively correlated with OLR, especially over large ocean basins and arid regions in Australia, Saharan Africa, and the Middle East. Conversely, a positive correlation is seen over the western Pacific warm pool region. The negative correlation between VE and OLR might be directly linked to the global cooling parasol effects, whereas the positive correlation is more difficult to explain. Large VEs release large amounts of sulfur gases, which transform to sulfate aerosols. The aerosols can reach the stratosphere and linger there, with an $e$-folding residence time of approximately 1 year. The aerosols scatter some solar radiation back to space, thus cooling the surface (Robock 2000). In this analysis period, two large VEs (El Chichón in 1983 and Pinatubo in 1991) coincide with strong El Niños (Self et al. 1997), such that a slight similarity with the El Niño pattern comes up in the MLR analysis. With this relatively short period of data, correlation between VE and ENSO has been found to be largely coincidental (Self et al. 1997; Robock 2000).

- The coefficients of hypothetical LT (Fig. 2j) are dominantly positive with the wider areas in the Northern Hemisphere, except for some limited areas showing negative values in the tropics. If we can ignore the possible influence of the orbital drift and changes in instrument characteristics across the observational record, there are two possible explanations of the positive trend; the first could be indicative 
(a) OMI

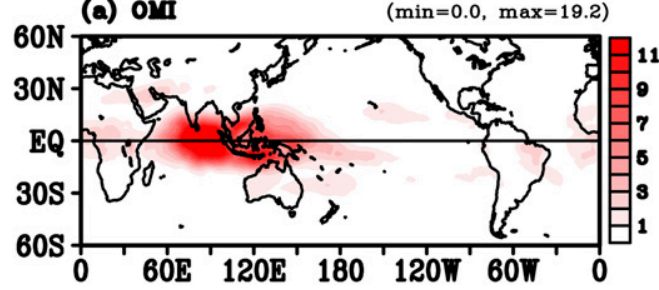

(c) DMI

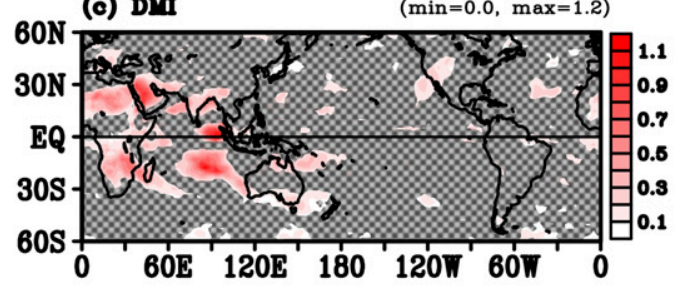

(e) TSI

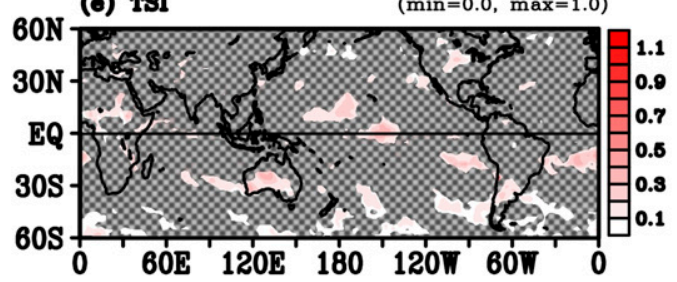

(a) LT

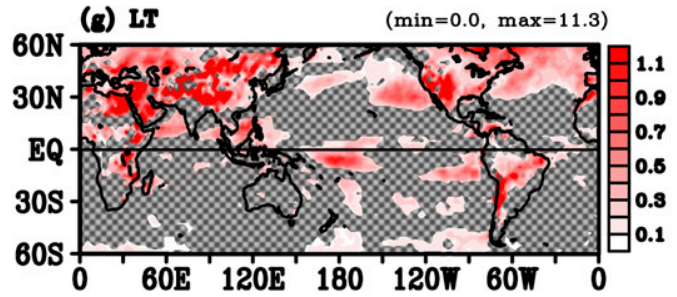

(b) QBO $\left(\theta_{2}=40^{\circ}\right)$

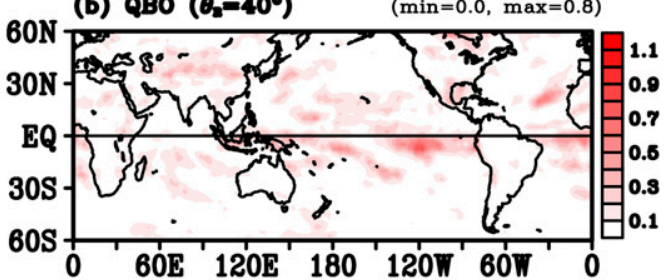

(d) NnNo 3.4 SsTA

$(\min =0.0, \max =20.3)$

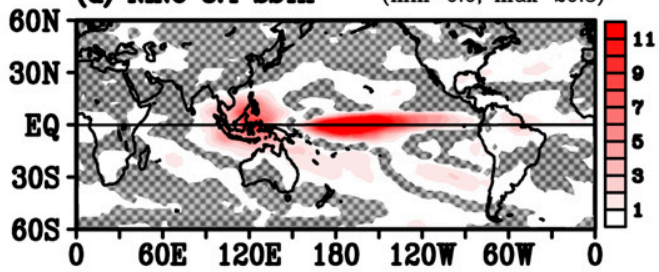

(s) SAOD

$(\min =0.0, \max =3.2)$

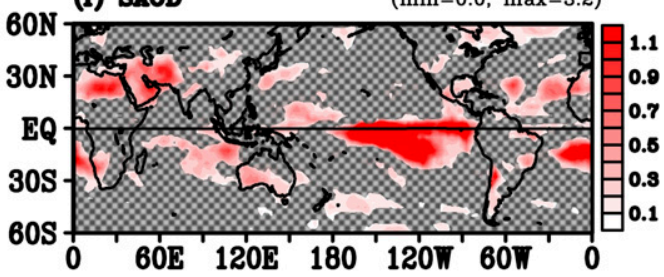

(h) aum of (a)-(c)

$(\min =0.0, \max =22.7)$

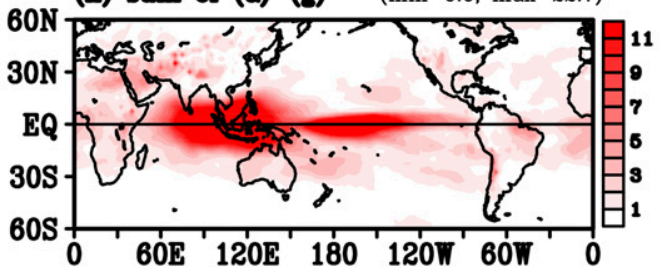

FIG. 3. Spatial distribution of explained variance (\%) of (a) OMI, (b) QBO $\left(\theta_{R}=40^{\circ}\right)$, (c) DMI, (d) Niño-3.4 SSTA, (e) TSI, (f) SAOD, (g) LT, and (h) total of (a)-(g). Hatched regions in (c)-(g) are similar to Figs. $2 \mathrm{f}-\mathrm{j}$, respectively. Minimum and maximum values of each plot are given at the top-right corner. Color scale for (a), (d), and $(\mathrm{h})$ is one order larger than the rest of plots.

of decreasing in cloud fraction. Another possibility is warming near the surface in clear-sky conditions.

- The regression constants $\beta_{0}$ (Fig. 2a) clearly indicate a significant positive bias over the Saharan Africa and Middle East regions. On the other hand, time averages of the absolute and standard deviations of residuals show maximum values over areas around the $\mathrm{MC}$ and western Pacific warm pool, the ITCZ (intertropical convergence zone), and the SPCZ, where convective activities are more dominant (Figs. 2k,l).

An important measure for the performance of regression is explained variance. The explained variance of each predictor is defined by percentage ratio of reconstructed variance to total input variance (i.e., the variance of the predictand). As standardized predictors are used, the reconstructed variance of each predictor is the regression coefficient squared. For the MJO and
QBO, the reconstructed variance is defined by the sum of the two OMIPCs and QBOPCs squared coefficients, respectively. Meanwhile, the total explained variance is the sum of the explained variance of all predictors. A perfect regression has the total explained variance equal to $100 \%$ and perfectly explains the total input variance. On the other hand, a small value of the total explained variance expresses that the regression explains only a small portion of the total input variance. This can happen when the nature of unexplained variance is large, which is possibly due to nonlinear cross terms of predictors or random noise by internal variability.

To assess the relative importance of the source of variability, Figs. $3 \mathrm{a}-\mathrm{g}$, respectively, show explained variance for the OMI, QBO, DMI, Niño-3.4 SSTA, TSI, SAOD, and LT. The maximum values of the explained variance of OMI and Niño-3.4 SSTA are comparable (note that the color scale for these plots is one order 

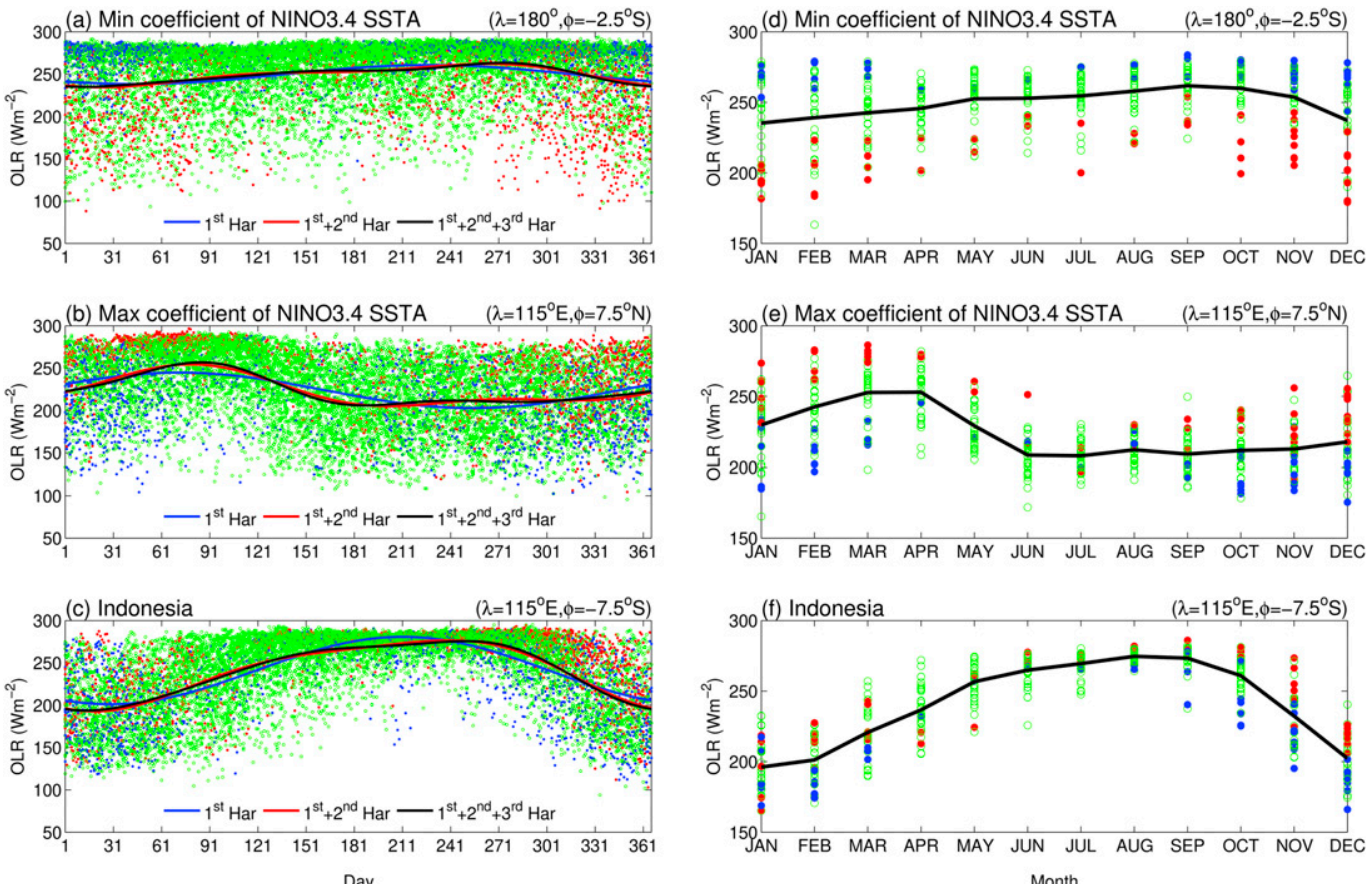

FIG. 4. Scatterplots of (left) daily and (right) monthly OLR for $35 \mathrm{yr}$ (1979-2013) over three point locations; (a),(d); (b),(e); and (c),(f), respectively, correspond to points o, p, and q marked by yellow crosses in Fig. 2g. Lines in the left panel show the first harmonic (blue), and combinations of the first two (red) and first three (black) harmonics of annual cycle. Black lines in the right panel show long-term climatology of monthly averages. Red, blue, and green circles show El Niño, La Niña, and neutral conditions, respectively.

larger than the rest of plots). For OMI, high values of explained variance are observed over the Indian Ocean to the western Pacific Ocean. Meanwhile, for Niño-3.4 SSTA, high values of explained variance are observed over the $\mathrm{MC}$ and the central to the eastern Pacific Ocean. On the other hand, the QBO appears to contribute the least to OLR variability (Fig. 3b). Figure 3h describes the total explained variance, which is dominant over tropics, from the Indian Ocean to the eastern Pacific Ocean.

We carried out further analyses on AC modulation of the ENSO-OLR correlation in the tropics by selecting three grid points that are cross-marked and labeled "(o)", "(p)", and "(q)" in Fig. 2g, which represent areas of minimum (negative) and maximum (positive) values in the regression coefficients, and an additional point over Indonesia in the Southern Hemisphere, respectively. Corresponding to each of the locations, Fig. 4 shows scatterplots of daily OLR data (left panel) with decomposition and the sum of harmonics of the annual cycle, and monthly OLR data (right panel) with the mean annual cycle (see figure caption). Note that the colors of the circles in Fig. 4 are associated with El Niño (red), La Niña (blue), and neutral (green) conditions. Following Nishimoto and
Yoden (2017), the El Niño (La Niña) phase is defined when Niño-3.4 SSTA is greater (less) than $1.0^{\circ} \mathrm{C}$ $\left(-1.0^{\circ} \mathrm{C}\right)$.

Overall, Figs. $4 \mathrm{a}-\mathrm{f}$ confirm the relationship between Niño-3.4 SSTA and OLR, indicating that OLR values are lower (higher) than the climatology during El Niño (La Niña) events over the central Pacific [point (o)], (e.g., Wang et al. 1999). For daily data, Fig. 4a shows smaller annual variations than Fig. $4 b$ for point (p) and Fig. $4 \mathrm{c}$ for point (q), and the annual variation of Fig. $4 \mathrm{~b}$ is out of phase compared with that in Fig. 4c. This difference indicates the dominant influences of Asian and Australian monsoons over points (p) and (q), respectively. Thus, strong correlation between ENSO and OLR in these tropical regions is largely controlled by seasonal variations known as the monsoons. Similar patterns are also seen in monthly data (right panels of Fig. 4). It can be observed in Fig. 4d that the separation of El Niño and La Niña modulation is pronounced through the year over point (o). Conversely, Fig. 4e for point (p) and Fig. 4f for point (q) show that the separation of El Niño and La Niña modulation in the extended boreal winter (i.e., from October to March) is more pronounced than in the boreal summer for both Asian and Australian monsoons. 


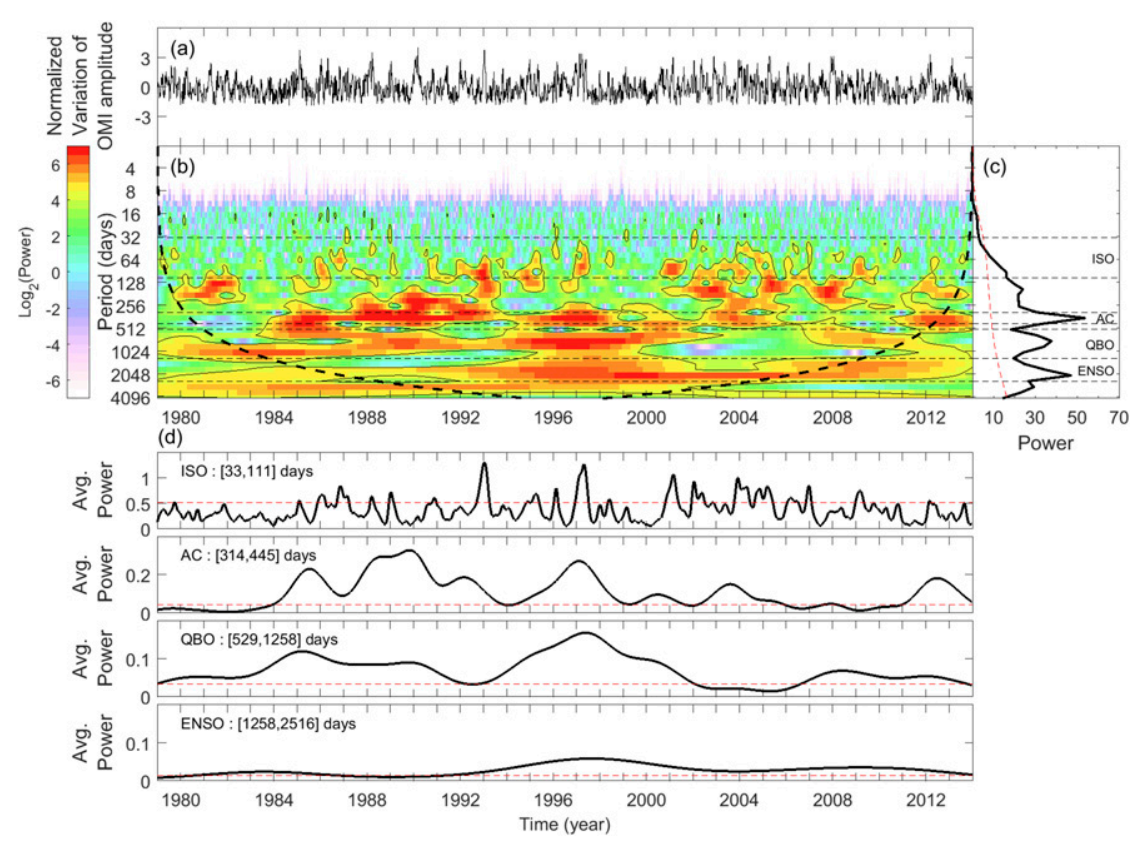

FIG. 5. (a) Time series of daily normalized variation of OMI amplitude from 1979 to 2013. (b) Wavelet power spectra of (a) analyzed using Morlet wavelet with thick dashed line indicating the cone of influence (COI). (c) Global wavelet spectrum (GWS). (d) Scale averaged wavelet power over intraseasonal oscillation (ISO), annual cycle (AC), QBO, and ENSO with corresponding periods shown in each panels. Statistical significance is expressed as $95 \%$ confidence level indicated by contours in (b), and red dashed lines in (c) and (d).

\section{b. Contributions of atmospheric oscillations on tropical OLR variations}

From the previous results, it becomes clear that the largest components of OLR variations belong to the tropics. The previous result also suggests that there should be modulations of AC or seasonal variations by atmospheric oscillations, such as ENSO, in the tropics. In this subsection, OLR data are inspected and interpreted to understand the relative contributions of four time-scale oscillatory signals (i.e., ISO, AC, QBO, and ENSO) using wavelet analyses. We apply wavelet analyses to OMI, a parameter that is independent from the longitudinal variations, that may encapsulate the four oscillatory components.

Figure 5 shows the time series of daily normalized variation of OMI amplitude for the 35-yr period of 1979-2013 (Fig. 5a), the corresponding wavelet spectrogram (Fig. 5b), the global wavelet spectrum (GWS; Fig. 5c), and the scaled and averaged wavelet power for the four oscillatory signals of interest (Fig. 5d). The spectral power is nondimensional and represents the variance as the square of standard deviations. The thick dashed line overlaid on the color-coded spectrogram indicates the cone of influence (COI), under which edge effects become important and estimates of wavelet coefficients are not completely reliable (Torrence and Compo 1998). Temporal structures of the spectra are shown in Fig. 5d, where ISO, AC, QBO, and ENSO are respectively represented by the averaged power over frequency bands corresponding to the periods of 33-111, 314-445, 529-1258, and 12582516 days. Note that the variations associated with the QBO time scale are not necessarily synchronized with the stratospheric QBO but are obtained as a tropospheric signal defined with the time series of OMI amplitude.

The spectrogram and GWS of Figs. $5 \mathrm{~b}$ and $5 \mathrm{c}$ show that AC contributes the most, followed by ENSO, QBO, and ISO. The ISO signature of OMI amplitude modulation is not very strong, whereas the modulations by other oscillatory signals are stronger. As is also evident in the wavelet power spectra, OMI appears to have large noise components in the ISO frequency band, with more sporadic power enhancements during the periods from 1986-98 and 2001-10. Conversely, the statistically significant power of AC signals is quite pronounced and almost persistent, except in some years during the initial period and during 2006-11. However, the scaleaveraged power seems to indicate that longer period oscillations of QBO and ENSO are more persistently significant. It can also be seen that ENSO modulations 

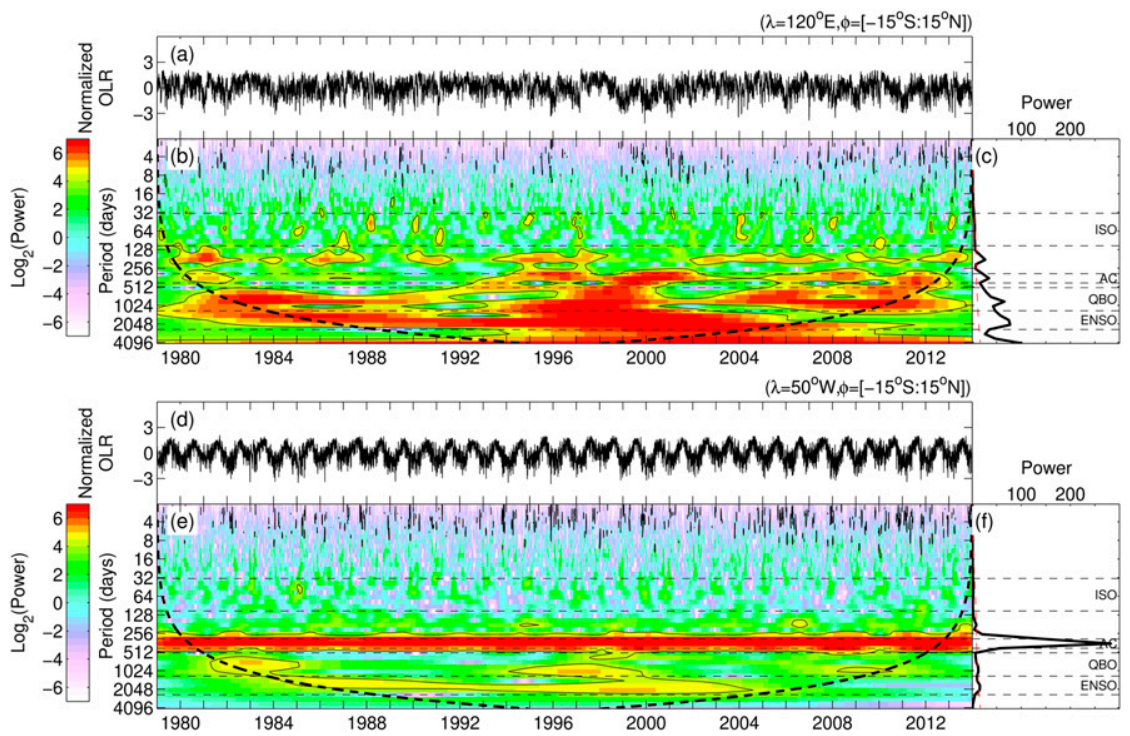

FIG. 6. (a)-(c) As in Figs. 5a-c, respectively, but for daily normalized OLR over longitude $120^{\circ} \mathrm{E}$ averaged for latitude from $15^{\circ} \mathrm{S}$ to $15^{\circ} \mathrm{N}$. (d)-(f) As in (a)-(c), but for longitude $50^{\circ} \mathrm{W}$.

are dominant during 1996-2000, presumably owing to the strong 1997/98 El Niño event (Fig. 1d).

We further applied wavelet analyses on the normalized daily OLR averaged over tropical latitudes of $15^{\circ} \mathrm{S}$ to $15^{\circ} \mathrm{N}$. As an example, Figs. $6 \mathrm{a}-\mathrm{c}$ show the daily time series of OLR at $\lambda=120^{\circ} \mathrm{E}$ (Fig. 6a) and its wavelet spectrogram (Fig. 6b) with GWS (Fig. 6c). Time variations of the OLR at a particular longitude look very different from the amplitude modulation of OMI, whereas the scale averaged power shows highly significant peaks for ENSO, QBO, AC, and semiannual cycle. Note that the time series is mean-centered and normalized, so the spectral power is nondimensional and represents the variance as the square of standard deviations. The red dashed line in the GWS and black solid line contours in the spectrogram indicate statistical significance with a $95 \%$ confidence level. Figures $6 d-f$ show the same plots, except for $\lambda=50^{\circ} \mathrm{W}$, where AC signal dominates. Weak modulations are seen in QBO and ENSO time scales around 1983, 1998, and 2010.

To investigate longitudinal variations, the GWS for each longitude is shown in Fig. 7. It can be seen from Fig. 7a that AC signals appear at almost all longitudes with relatively strong amplitude over the Indian Ocean through MC, which would represent the effects of monsoons. Moreover, stronger AC signals appear over

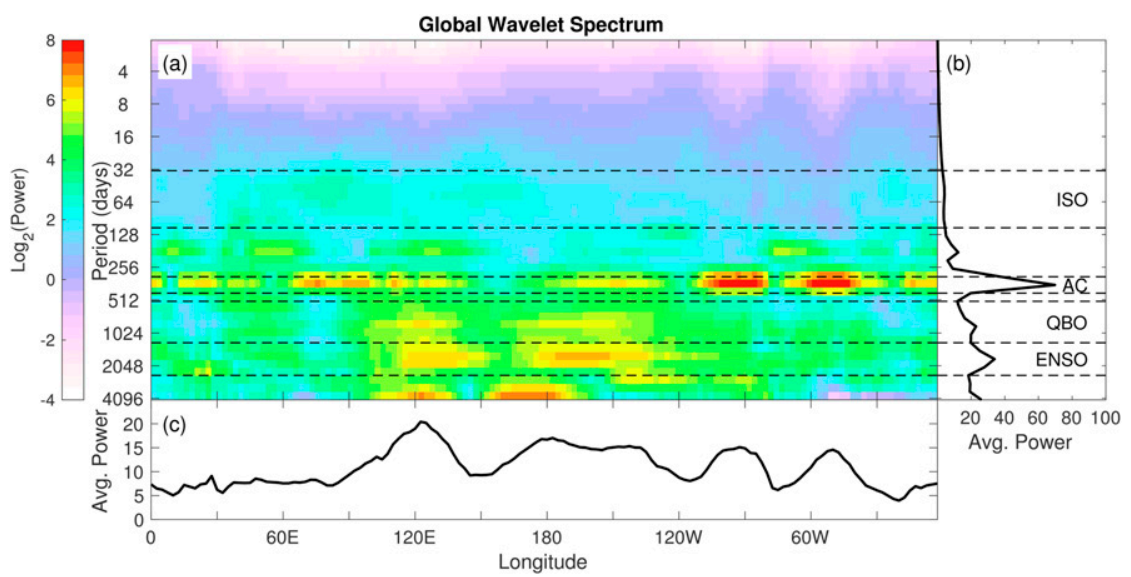

FIG. 7. (a) Global wavelet spectrum (GWS) as in Fig. 5c but for daily normalized OLR of each longitudinal grid averaged over $15^{\circ} \mathrm{S}-15^{\circ} \mathrm{N}$. (b) Average of (a) over longitude. (c) Average of (a) over period. Black dashed lines in (a) and (b) show periods of ISO, AC, QBO, and ENSO frequency bands. 
(a) ISO Power : $[33,111]$ days

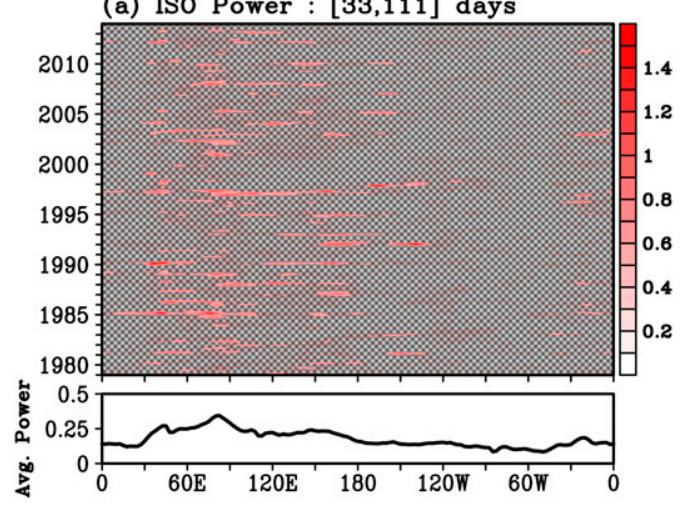

(c) QBO Power : $[529,1258]$ days

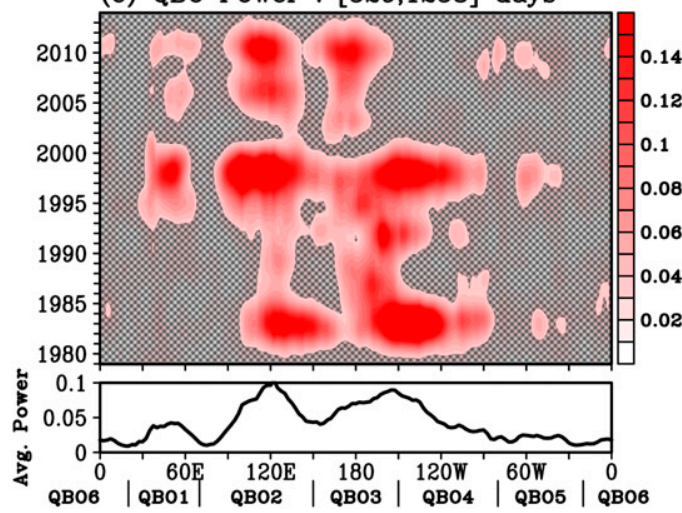

(b) AC Power : $[314,445]$ days

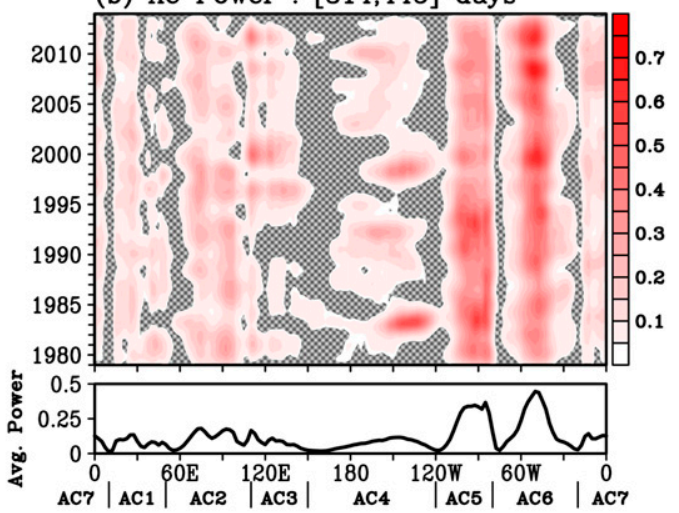

(d) ENSO Power : $[1258,2516]$ days

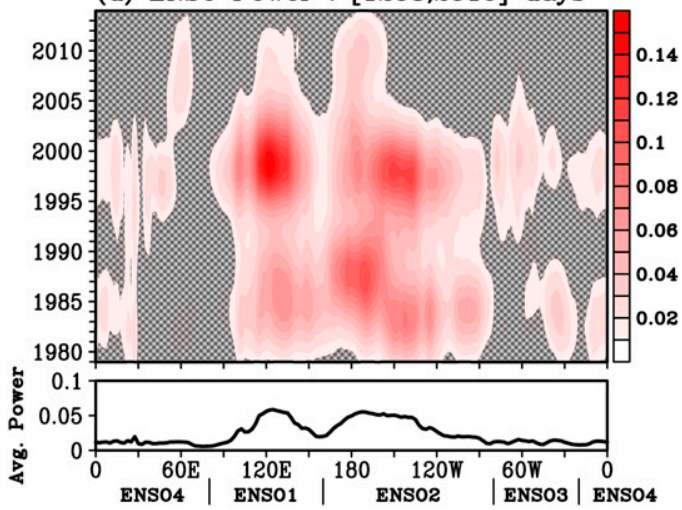

FIG. 8. Hovmöller plots of (a) ISO, (b) AC, (c) QBO, and (d) ENSO power. Hatched regions indicate those with confidence level below $95 \%$. The graphs below each panel are the time-averaged power. Codes between vertical bars below (b)-(d) show regions for the next analysis in Fig. 12.

the longitudes of eastern Pacific (around $90^{\circ} \mathrm{W}$ ) and South America (around $60^{\circ} \mathrm{W}$ ). This appears to occur because, in those longitudes, spectral powers are concentrated mainly on AC. Over MC, on the contrary, high spectral powers are more distributed into ENSO and QBO frequency bands. Figure 7a also indicates that the longitudes of strong OLR-defined QBO spectra appear in conjunction with those of ENSO.

The temporal structure of wavelet coefficients for each oscillation has not been elaborated in Fig. 7 . Therefore, instead of GWS, we plot scale-averaged power for the oscillations (similar to that of OMI in Fig. 5d, but for OLR data for each longitude) as Hovmöller diagrams in Fig. 8, together with the time averages of the power. Hatched areas indicate those below a $95 \%$ confidence level. Now it becomes clearer, in Fig. $8 \mathrm{a}$, that the strength of the ISO signal is mainly restricted over the longitudes of the Indian Ocean through the Pacific Ocean, although relatively small but significant spectral power also exists over the Atlantic near the Greenwich longitude. ISO power occurrences do not show a strong regular pattern, but there are notable interannual to interdecadal variations.
Figure $8 \mathrm{~b}$ shows significant $\mathrm{AC}$ power locked over the longitudes of Africa and the Indian Ocean, as well as the MC, central Pacific, eastern Pacific, South America, and Atlantic Ocean. The characteristics of AC in these seven locations (marked by ACn, $n=1, \ldots, 7$ ) will be discussed in further detail (see Figs. 10 and 12). As previously observed in Fig. 7, the strongest AC signals appear over the eastern Pacific and South America, with almost constant amplitudes over the analyzed period because of weak modulations by other signals. Over the Indian Ocean, AC power is relatively persistent with some interannual variations, whereas signal modulations at lower frequencies are stronger over the $\mathrm{MC}$ and central Pacific. It should be noted that the AC signal over the MC is somewhat disrupted during 1982-93, likely after the strong 1982/83 El Niño event.

Figures $8 \mathrm{c}$ and $8 \mathrm{~d}$ show Hovmöller diagrams of OLRdefined QBO and ENSO powers, respectively, which indicate similar gross features. It can be observed that strongly coupled spectral powers of QBO and ENSO are associated with a sequence of ENSO events from 1996 to 2000. This and previous results confirm that QBO signals show dependency on ENSO, or are manifestations 

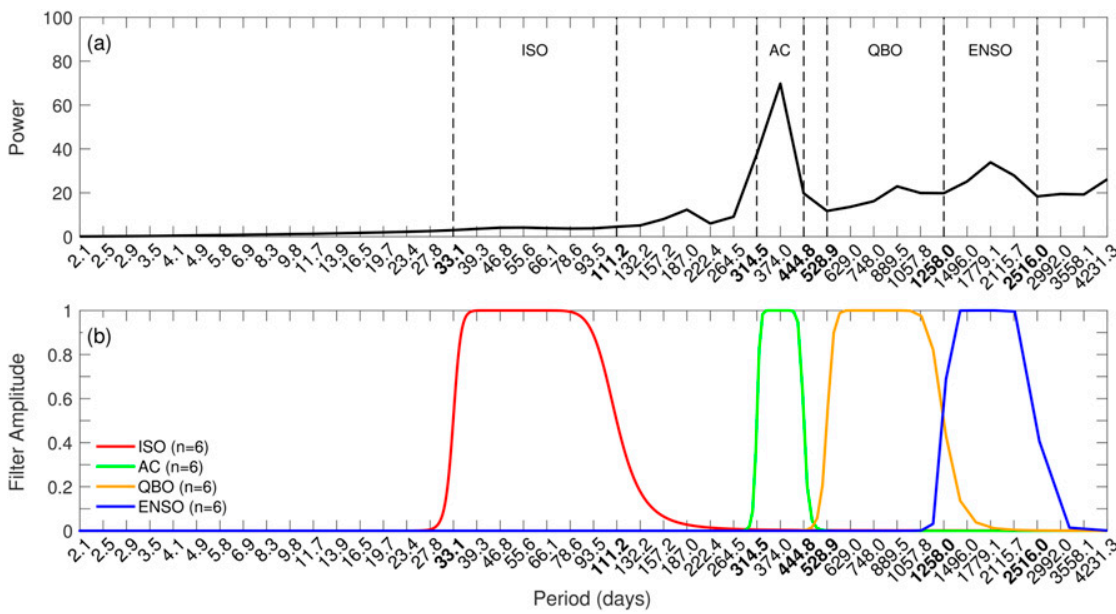

FIG. 9. (a) As in Fig. 7b. Dashed lines show periods of ISO, AC, QBO, and ENSO. (b) Sixthorder $(n=6)$ Butterworth bandpass filter designs for ISO, AC, QBO, and ENSO with periods of the bandpass frequencies printed in bold.

of ENSO modulation itself (see also Fig. 7a). Either way, the QBO signatures revealed by the wavelet analysis directly pertain to tropospheric variations of OLR. For further analyses, similar to Fig. $8 \mathrm{~b}$, longitudes where significant spectral powers occur are marked as QBOm, $m=1, \ldots, 6$ and ENSO $n, n=1, \ldots, 4$ in Figs. $8 \mathrm{c}$ and $8 \mathrm{~d}$, respectively. Over the central and eastern Pacific, there are two QBO locations (QBO3 and QBO4) analyzed because the longitudinal extent of the QBO power is different after and before 2000 over the central to eastern Pacific.

\section{c. Temporal and spatial structures of oscillatory signals}

Results of the wavelet analyses provide useful insight into the spectral content of OLR data, but real amplitude variations of the four oscillatory signals have yet to be inspected. One could actually use wavelet filtering and wavelet inverse transforms to obtain an oscillatory time series. However, we consider it more practical to apply bandpass filtering on the time series of OLR. Figure 9 shows the design of the sixth-order Butterworth filter described in section $2 b(3)$, and the results are discussed below.

Corresponding to Figs. 8a-d, Figs. 10a-d present Hovmöller plots of ISO-, AC-, QBO-, and ENSOfiltered and normalized OLR for each longitudinal grid along the equator averaged over $15^{\circ} \mathrm{S}-15^{\circ} \mathrm{N}$. Consistent with Fig. 8a, Fig. 10a shows a concentration of ISO signals over longitudes between $30^{\circ} \mathrm{E}$ and the date line, with variations in their east-west continuation. While the appearance of extremely prolonged signals is probably random, shorter ISO events appear to exhibit a subtle interdecadal variation. For instance, during the early 1990s, the population of short-lived ISO signals is relatively low and more concentrated around $90^{\circ} \mathrm{E}$ longitude. Widespread and increased population of longand short-lived signals appeared between 1995 and 1998, with the longest one occurring in 1997. ISO activities then decreased significantly west of $60^{\circ} \mathrm{E}$ longitude after 1998. From careful inspection, interdecadal patterns of enhanced and suppressed ISO activities can also be seen from Figs. 8a and 10a.

From Fig. 10b, it can be seen that the amplitudes of AC signals are quite persistent over the eastern Pacific (AC5) and tropical South America (AC6), with out-ofphase correlation. Between the Indian Ocean (AC2) and MC (AC3), continued and discontinued oscillatory patterns occur intermittently. To a lesser degree, similar patterns also occur over the Atlantic and Africa (AC7 and $\mathrm{AC} 1$ ). Over the central Pacific (AC4), between $150^{\circ} \mathrm{E}$ and $120^{\circ} \mathrm{W}, \mathrm{AC}$ amplitudes clearly exhibit decadal variations and are almost completely detached from other signals. However, disruptions of AC amplitudes over the MC that occurred from 1989 to 1994 appear to be teleconnected with the AC enhancement in AC4 area. As is also evidenced by the ISO-filtered signals, decadal and interdecadal variations of AC amplitudes are an important low-frequency modulator in OLR variations, particularly in these longitudes in AC3 and $\mathrm{AC} 4$ areas.

Figures $10 \mathrm{c}$ and $10 \mathrm{~d}$ show a strong coupling between QBO and ENSO time-scale signals, which is consistent with the patterns of spectral powers in Figs. 8c and 8d. However, the association between QBO and ENSO time-scale signals is weaker from 2000 to 2010, especially over the MC and western Pacific. It is worth noting that at least two ENSO Modoki events (e.g., Weng et al. 
(a) ISO-filtered Normalized OLR

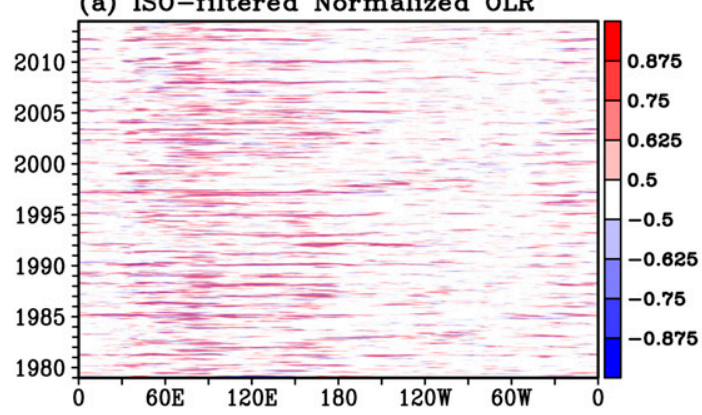

(c) QBO-filtered Normalized OLR

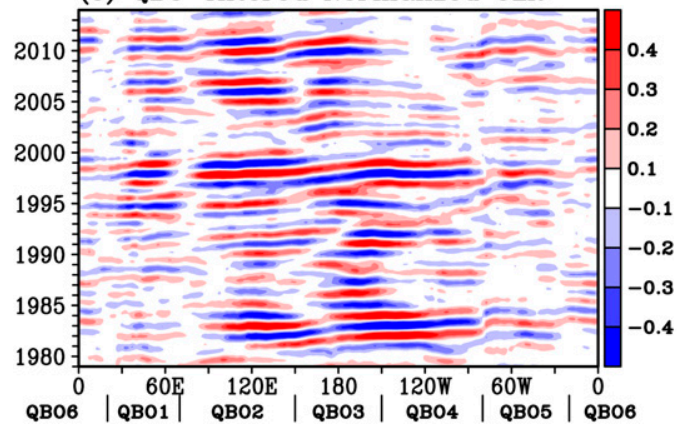

(b) AC-filtered Normalized OLR

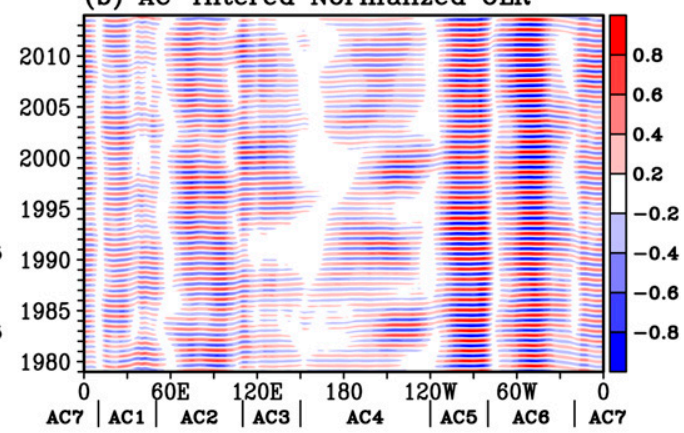

(d) ENSO-filtered Normalized OLR

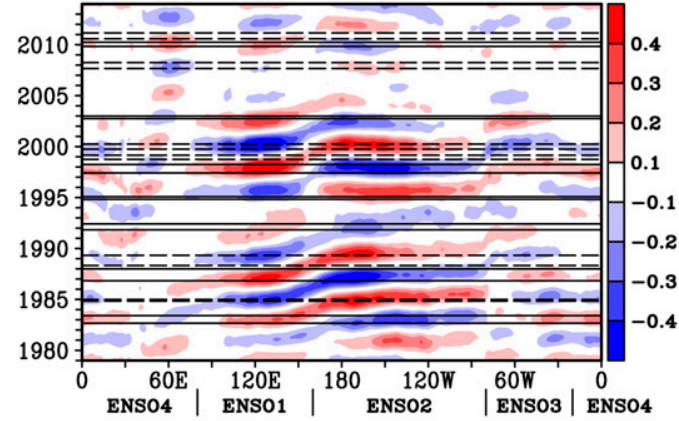

FIG. 10. Hovmöller plots of (a) ISO-, (b) AC-, (c) QBO-, and (d) ENSO-filtered daily normalized OLR averaged over $15^{\circ} \mathrm{S}-15^{\circ} \mathrm{N}$. Horizontal solid (dashed) lines in (d) indicate El Niño (La Niña) periods. Codes between vertical bars below (b)-(d) show regions for the next analysis in Fig. 12.

2007; Ashok et al. 2007) have been identified during this period.

Figures 8 and 10 reveal that modulations, coupling, and teleconnections among the phenomena mainly occur across the longitudes from Indian Ocean to central Pacific. Moreover, the ENSO-monsoon interaction is part of the intrinsic characteristics of the climate in this region. As AC is a fundamental characteristic of the monsoon, we analyze the AC-filtered time series (Fig. 10b) in more detail by breaking it into four seasons, as depicted in Fig. 11. Figures 11a and 11c clearly show the contrast in AC phases between the Northern Hemisphere winter (DJF) and summer (JJA). Figure $11 \mathrm{~b}$ for MAM shows that the AC signals in AC2 and 5 (AC4 and 6) have the same positive (negative) sign as that in the extended dry (wet) season for DJF (Fig. 11a), whereas the corresponding signs for JJA (Fig. 11c) and SON (Fig. 11d) are opposite due to the extended wet (dry) season. On the other hand, the AC component does not show any similar signals of extended wet or dry seasons in Africa (AC7 and $\mathrm{AC} 1$ ) or in MC (AC3). The AC-filtered DJF-JJA OLR anomalies show some pairing regions with opposite phases that are attributed to monsoons in the Indo-Pacific (AC2, AC3, AC4), South America (AC5, AC6), and Africa $(\mathrm{AC} 7, \mathrm{AC} 1)$. The Indo-Pacific region is quite unique, mainly consisting of the Indian Ocean (AC2) and MC (AC3) with remote extension to the central Pacific (AC4). In the Indo-Pacific region, AC signals show rather complex interannual to decadal variations, with changing patterns of enhancement and disruption. From 1989 to 1994, disruption of AC amplitudes over MC occurred in conjunction with interdecadal enhancement in the central Pacific.

Finally, Fig. 12 shows the unfiltered (Fig. 12a) and filtered (Figs. 12b-d) OLR time series, averaged over longitudes marked under Figs. 8b-d and 10b-d. Now details about decadal modulation become clearer, including that, for example, AC amplitudes over MC (AC3) nearly vanished from 1990 to 1993. Also, the amplitudes after 1993 are larger than the amplitudes before 1990. Conversely, AC amplitudes over the AC5 and AC6 regions are nearly constant. It can also be observed that ENSO phases are strictly of opposite sign between the MC (ENSO1) and central Pacific (ENSO2) regions as a fundamental nature of ENSO, while ENSO signals over America (ENSO3) are nearly in phase with those of ENSO1 with a smaller amplitude. Such phase-locking characteristics are also evident in the QBO signals of the $\mathrm{MC}(\mathrm{QBO} 2)$ and central Pacific (QBO3), indicating a modulating effect by the El Niño events. However, QBO signals in the two regions still show strong amplitudes 
(a) DJF

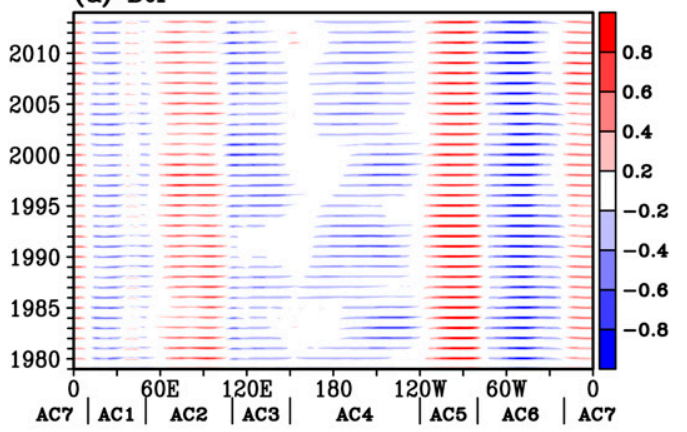

(c) JJA

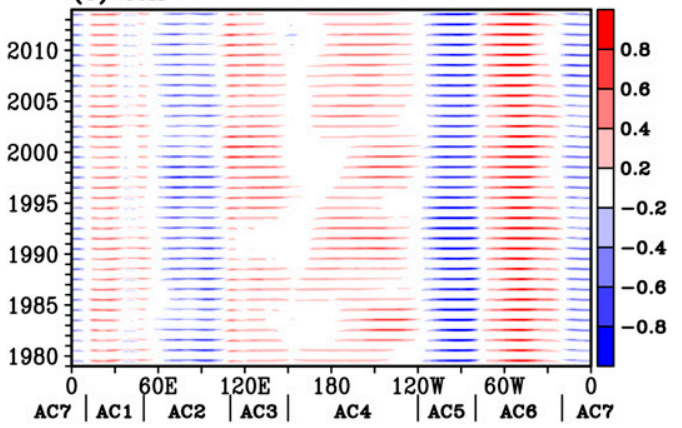

(b) MAM

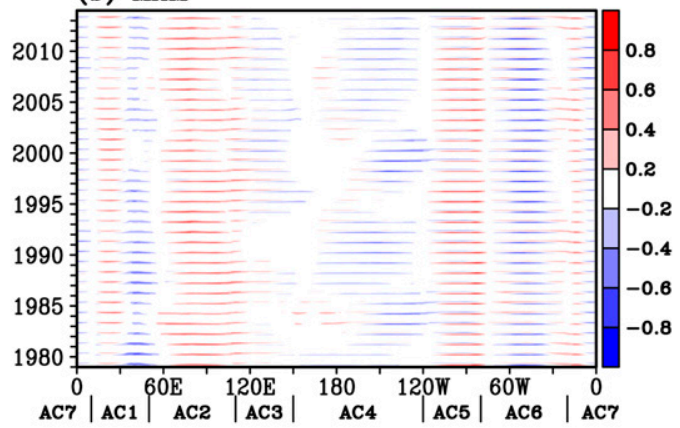

(d) SON

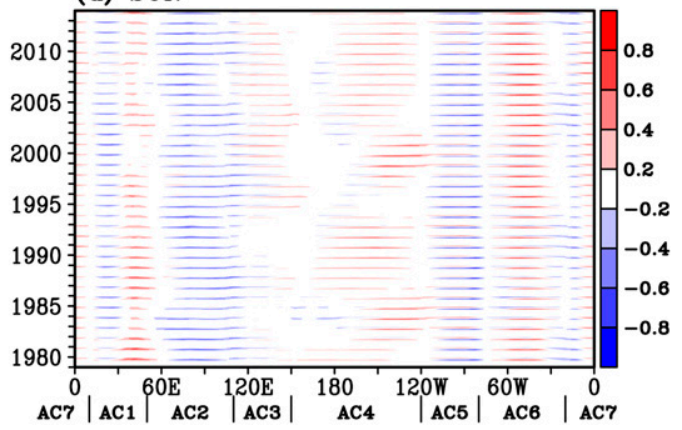

FIG. 11. AC-filtered daily normalized OLR averaged over $15^{\circ} \mathrm{S}-15^{\circ} \mathrm{N}$ for (a) DJF, (b) MAM, (c) JJA, and (d) SON. Codes between vertical bars below (a)-(d) show regions for the next analysis in Fig. 12.

during relatively quiet ENSO (with weaker events) periods after 2004. While still having tropospheric linkage, this may suggest the existence of OLR-defined QBO signals that are rather independent from ENSO.

\section{Discussion}

From the phenomenological descriptions in the previous section, AC is obviously a fundamental component of OLR variations in the tropics that seems to be mostly attributable to global monsoon systems. Although our interpretation concerning the monsoons is mainly based on latitudinally averaged amplitudes of AC signals (Fig. 8), the longitude groups (AC1 through AC7) can be compared with global monsoon regions of India (IN), East Asia (EA), the western North Pacific (WNP), Australia (AUS), North America (NAM), South America (SAM), northern Africa (NAF), and southern Africa (SAF), as defined by Yim et al. (2014), in which precipitation data have been analyzed. If the monsoonal regions of Yim et al. (2014) are projected on the equator, we can see the correspondence between SAF, IN, AUS, NAM, SAM, NAF and, respectively, AC1, AC2, AC3, AC5, AC6, and AC7. Moreover, precipitation in IN, NAM, and NAF peaks in JJA, whereas SAF, AUS, and SAM have peaks in DJF. This is consistent with our previous notes that $\mathrm{AC} 1, \mathrm{AC} 3$, and AC6 are modulated by the Southern Hemispheric summer monsoons (blue in Fig. 11a) whereas AC2, AC5, and AC7 are modulated by the Northern Hemispheric summer monsoons (blue in Fig. 11c).

Figures 10-12 clearly show that AC amplitudes and phases are most well defined over the longitudes of AC5 and AC6, representing the North and South American monsoons. These well-defined AC signals are the result of two factors: 1) the dominantly longitudinal migration of rainfall systems (see, e.g., Vera et al. 2006) and 2) the minimum contributions of other oscillatory signals (MJO, QBO, and ENSO) to OLR variations. This implies that long-term trends in the strength of AC signals may also be well defined; it is quite interesting that wavelet power spectra in Fig. 8 seem to indicate that over AC5, the AC signal weakens with time and vice versa over AC6. Vera et al. (2006) show that JanuaryMarch rainfall data observed from 1948 to 1999 in southern Brazil exhibit an increasing trend (with higher increases from 1976 to 1999), which is consistent with the strengthening of AC signals over AC6. Conversely, the weakening of the signal in AC5 (that corresponds to the North American monsoon) during the last several decades agrees with results from recent numerical study by Pascale et al. (2017) on the effects of global warming.

In regions other than AC5 and AC6, especially in AC3 and $\mathrm{AC4}$, which correspond to the MC and western 

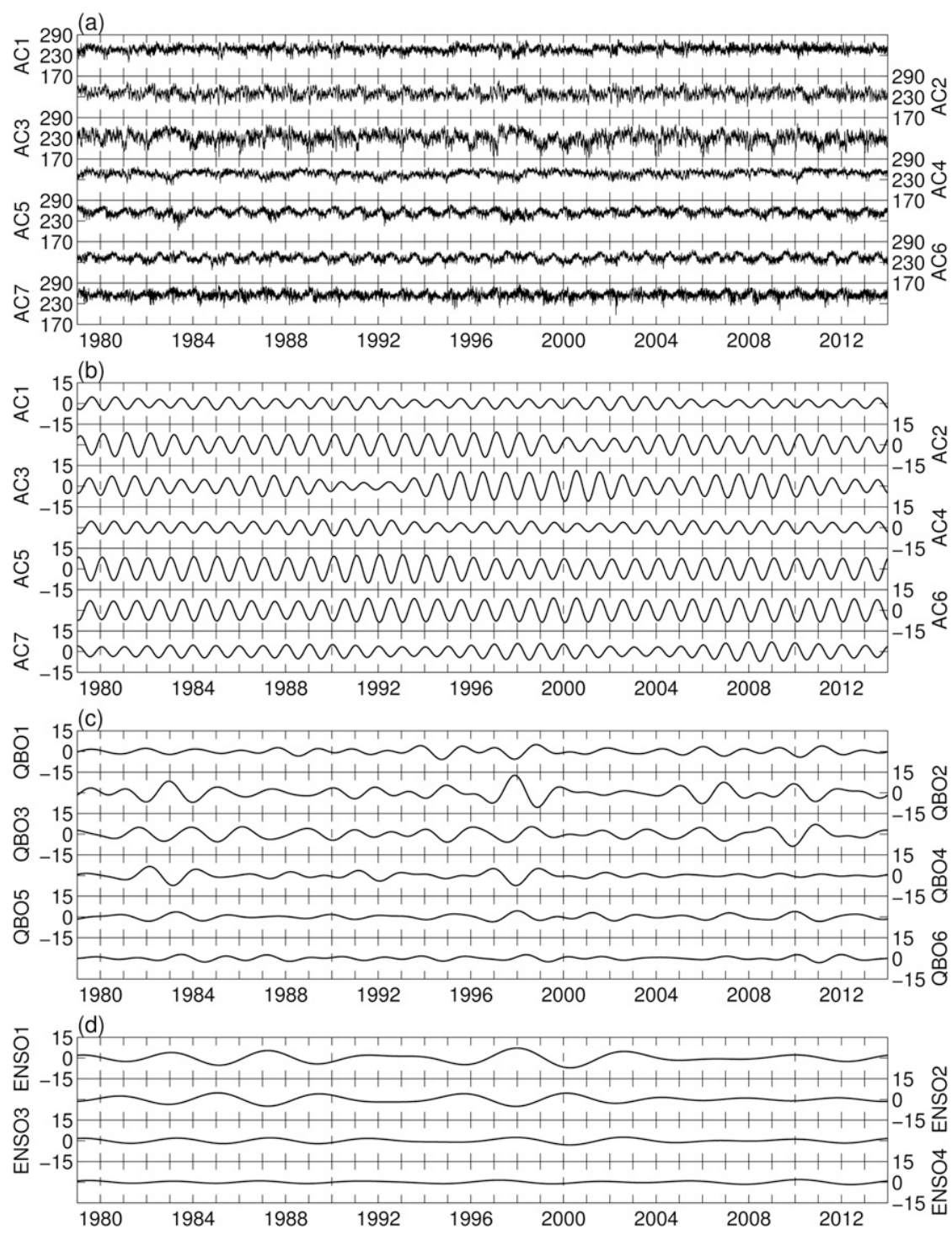

FIG. 12. (a) Area averaged of daily OLR and (b)-(d) results of bandpass filtering at AC, QBO, and ENSO frequency respectively. The units of (a)-(d) are in $\mathrm{W} \mathrm{m}^{-2}$. The longitudes for averaging are defined in Figs. $8 \mathrm{~b}-\mathrm{d}$ or $10 \mathrm{~b}-\mathrm{d}$, as indicated by the codes, for the latitude of $15^{\circ} \mathrm{S}-15^{\circ} \mathrm{N}$.

Pacific, trends in AC amplitudes are more difficult to define. In this case, the MLR result that shows spatially alternating patterns of positive and negative trends (Fig. 2j) is not likely associated with long-term variations in AC amplitudes. Thus, we must consider contributions from other oscillatory signals. In particular, as shown in Fig. 8, the strength of QBO and ENSO time-scale signals are quite dominant in the regions.

As mentioned previously, QBO- and ENSO-filtered signals in general show strong interdependence, whereas the OLR-defined QBO signal itself does not appear to be particularly correlated with the QBO indices derived from the data for stratospheric winds. It should also be noted that previous studies (Yoo and Son 2016; Nishimoto and Yoden 2017; Son et al. 2017) revealed a seasonally dependent correlation between the stratospheric QBO with OLR-defined MJO (not QBO). Taking another view, our results suggest that the QBO signals in the OLR data are mainly of tropospheric origin, rather than stratospheric origin, consistent with MLR results that showed little projection on the QBO indices. Figure 7a shows that strong signals from QBO and ENSO time scales are in similar longitudes. In addition, Figs. $8 \mathrm{c}$ and $8 \mathrm{~d}$ indicate similar gross features of OLR-defined QBO and ENSO. These results may be a hint of QBO signals as manifestations of ENSO. 


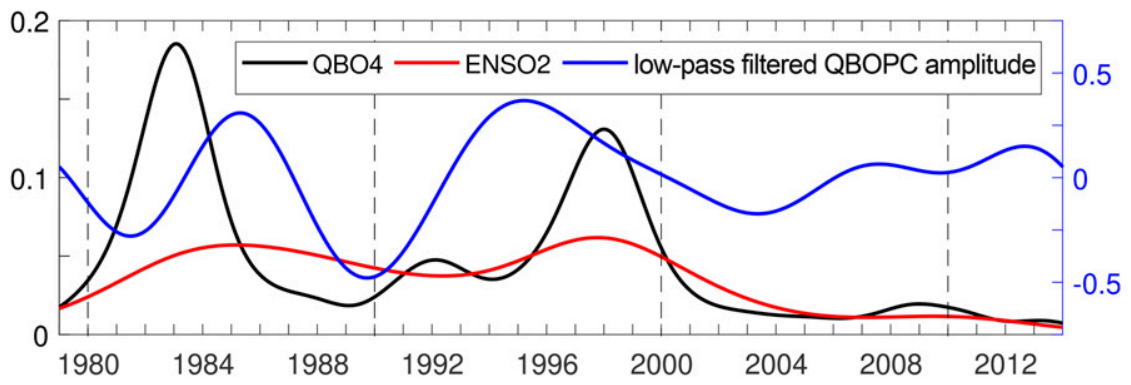

FIG. 13. Longitudinal average of QBO4 (black) and ENSO2 (red) power from Figs. 8c and $8 \mathrm{~d}$, respectively, with the $y$ axis on the left side superimposed with QBOPC amplitude $\left(\sqrt{\mathrm{QBOPC}^{2}+\mathrm{QBOPC}^{2}}\right)$ normalized and low-pass filtered for frequency lower than ENSO (blue) with the $y$ axis on the right side.

However, there are two separated peaks in the interannual time scale, which we defined as the QBO and ENSO time scales (Fig. 7b). Furthermore, with regard to ENSO, there are conventional and Modoki (Ashok et al. 2007) types of El Niño. Several typical El Niño Modoki events occurred in 1986, 1990, 1991, 1992, 1994, 2002, and 2004. Figures 8 and 10 indicate that the last two events occurred during a notably quiet ENSO period from 2000-10. Interestingly, the QBO amplitudes are still high over the longitudes of the $\mathrm{MC}$ and western Pacific warm pool (QBO2 and QBO3) during this period. As the signals are much more confined to the $\mathrm{MC}$ and western Pacific regions, and considering that the biennial mode is an intrinsic characteristic of the coupled monsoon-ENSO system (e.g., Wu and Kirtman 2004), we can conclude that the OLR-defined QBO is related via complex interactions between ENSO and Asian-Australian monsoons. This interpretation may be similar to the claim of tropospheric biennial oscillation of its own kind (e.g., Meehl and Arblaster 2002).

Another point of interest is the apparent modulation of decadal/interdecadal variations on all analyzed signals in Figs. 8, 10, and 12. Figure 10 shows that this signal of low-frequency variability seems to quasi-periodically change the longitudinal extent of the QBO and ENSO. Newman et al. (2016) comprehensively discussed oceanic and atmospheric phenomena related to the Pacific decadal oscillation (PDO), which includes PDO-ENSO correlation but without the QBO time scale. Meanwhile, decadal modulation of the stratospheric QBO influence has been discussed by Camargo and Sobel (2010) in association with changes in the QBO modulation of tropical cyclone (TC) activity in the Atlantic. The interdecadal variability of the stratospheric QBO and its effects on the troposphere have also been confirmed by $\mathrm{Hu}$ et al. (2012). Although we have argued that the stratospheric QBO and OLR-defined QBO are rather independent, correspondence between OLR-defined
QBO, ENSO, and decadal/interdecadal variability in the stratospheric QBO can be seen clearly in Fig. 13. This leads to one intriguing fact that decadal/interdecadal signal modulation affects both tropospheric and stratospheric variations, with an albeit weak linear correlation owing to inconsistent phases.

The NOAA OLR dataset is based on polar-orbiting platforms and narrowband observations. These OLR estimates are inferred from infrared window radiances [e.g., from the Advanced Very High Resolution Radiometer (AVHRR)] using theoretical narrow-tobroadband relationships, which introduces a number of uncertainties and biases. In addition, the data are from multiple different satellites, each with its own unique characteristics, such as sensor channels, ECT, and orbital drift rate. Owing to changes of ECT, twice daily OLR data consist of biases (Waliser and Zhou 1997). Another issue that possibly influences trend is incomplete of diurnal sampling (e.g., twice daily time resolution). Taylor and Loeb (2013) evaluated the effect of incomplete diurnal sampling on monthly OLR trends using CERES-Terra SYN Ed2rev1 (Clouds and the Earth's Radiant Energy System synoptic product edition 2 revision 1). They found that comparison of OLR trend from complete (3-hourly time resolution) and incomplete (twice-daily time resolution) diurnal sampling shows no statistically significant differences. However, this only addresses a minor concern about the diurnal cycle. It does not address some of the biases unique to the NOAA daily-averaged twice-daily OLR dataset, some of which may be impossible to quantify. Although the analyses of trends should be performed carefully (Lucas et al. 2001), if we can ignore such a possible influence of the orbital drift and changes in instrument characteristics across the observational record, there are two possible explanations of the positive trend shown in Fig. $2 \mathrm{j}$, decreasing cloud fraction or warming near the surface. Although we limit our OLR analysis 
to $60^{\circ} \mathrm{N}$, this positive trend seems to agree with the fact that Arctic sea ice cover is depleting at an alarming rate, which has become a global concern (e.g., Comiso et al. 2017).

From previous discussions, it should be clear that the 35-yr OLR dataset is remarkably useful to analyze recent climate variations and change. OLR data have been very useful for climate diagnostics and, with a longer record in the future, it could be considered as standard unconventional data for analyzing climate change to complement conventional data of air temperature, rainfall, SST, and other variables.

\section{Conclusions}

In this study, we investigated the contributing factors to spatiotemporal patterns of OLR variations using a 35yr record (1979-2013) of gridded OLR data (Liebmann and Smith 1996). We employed three methods for analyzing the OLR data (i.e., MLR, wavelet transform, and bandpass filtering). Results of the MLR analysis are regression coefficients that can be used as a measure of correlation between predictors and OLR data (Fig. 2). In this case, three predictors (i.e., TSI, SAOD, and hypothetical linear trend) are considered as external factors. As shown in Figs. $2 \mathrm{~h}$ and 2i, TSI and SAOD show a widespread negative correlation with OLR, which could indicate cooling, enhanced convection, or increased cloud fraction, although we did not attempt to gain a deeper understanding from these results. Conversely, a positive trend of OLR that occupies the Northern Hemisphere could be related to decreasing cloud fraction or warming of the surface in global scales (Fig. 2j).

The remaining predictors in the MLR analysis are indices of ISO, stratospheric QBO, IOD, and ENSO, which are factors pertaining to internal dynamics of the climate system characterized by oscillatory signals. The regression coefficients show that ISO and ENSO have large influence on OLR variations as shown by the explained variance (Fig. 3). Two principal components of OMI have the largest influence over the tropics, particularly in the Eastern Hemisphere with an eastwardpropagating characteristics (Figs. 2b,c). ENSO signatures on OLR are exhibiting an El Niño dipole pattern over the MC and Pacific, with an extension to the Atlantic (Figs. $2 \mathrm{~g}$ and $3 \mathrm{~d}$ ), whereas strong influence of the IOD is much more concentrated in the Indian Ocean and Africa (Figs. 2f and 3c). Among all predictors, the stratospheric QBO indices show the weakest contribution (Figs. 2d,e, and $3 b)$. Overall, OLR responses over the tropics are broader and have larger-amplitude projections compared to those of the extratropical regions. High values of absolute residuals and their standard deviations also indicate the dominance of internal OLR variations over the tropics (Figs. 2k,1).

By employing wavelet transforms and bandpass filtering, we further investigated the contributions of the oscillatory signals relative to $\mathrm{AC}$, which is a fundamental component of OLR oscillations in the tropics. Timelongitude variations of AC amplitudes and phases averaged over $15^{\circ} \mathrm{S}-15^{\circ} \mathrm{N}$ clearly show pairs of contrasting JJA and DJF phases that characterize monsoon systems (Fig. 11). These results also indicate that the MC and Pacific regions are strongly coupled climatic regimes belonging to the same AC phase group with large interannual to decadal modulations. On the other hand, owing to minimum contributions of other factors, most consistent AC signals are found over the longitudes associated with North and South American monsoons, allowing us to interpret long-term trends in AC power.

Over the Indo-Pacific regions, strong interdependence is shown by wavelet spectra and OLR signals in the QBO and ENSO frequency bands (Figs. 8 and 10). However, the OLR-defined QBO signals over the MC and western Pacific regions $(\mathrm{QBO} 2$ and $\mathrm{QBO} 3)$ were still prominent during the relatively quiet ENSO period of 2000-10, and two El Niño Modoki events occurred during the period. Because the direct correlation between the stratospheric QBO and OLR variation is weak, as shown by the MLR analysis, our results indicate that the OLR-defined QBO is a manifestation of the complex interplay between tropospheric QBO, ENSO, and monsoon systems in the Indo-Pacific region, as indicated in Fig. 13.

Our results also show that all the analyzed oscillatory signals in OLR data are apparently modulated by decadal/interdecadal variations. This low-frequency variability appears to quasi-periodically change the longitudinal extent of ENSO and, also, particularly the OLRdefined QBO. For example, stronger QBO signals cover wider longitudes spanning to the Atlantic during the periods of 1981-85, 1993-2000, and to some extent, 2005-12 (QBO5 in Figs. 8c and 10c). These results confirm several findings from previous research about the effects of decadal/interdecadal variations on both stratospheric and tropospheric phenomena (i.e., Hu et al. 2012).

All our results suggest that the 35-yr record of OLR data is remarkably useful to analyze recent climate variations and change. With a longer record in the future, these data could be considered as standard unconventional data for studying climatic change, especially in aspects related to global-scale convective activities. Future studies should analyze bias-free OLR. Moreover, the techniques presented in this study could be fine-tuned and applied to evaluate modes of variability in climate and general circulation models. 
Acknowledgments. The authors are thankful to all anonymous reviewers for their critical and constructive comments on the manuscript of this paper. This work was supported by JSPS KAKENHI Grants JP15H05816 and JP17H01159 and the JSPS Core-to-Core Program, B. Asia-Africa Science Platforms, for FY 2015-17. This work was also supported by JSPS and the DG-RSTHE Joint Research Program for FY 2018-20. The first and second authors were also partially supported by 2017 ITB P3MI Research Grant.

\section{REFERENCES}

Ashok, K., S. K. Behera, S. A. Rao, H. Weng, and T. Yamagata, 2007: El Niño Modoki and its possible teleconnection. J. Geophys. Res., 112, C11007, https://doi.org/10.1029/ 2006JC003798.

Bretherton, C. S., M. Widmann, V. P. Dymnikov, J. M. Wallace, and I. Bladé, 1999: The effective number of spatial degrees of freedom of a time-varying field. J. Climate, 12, 1990-2009, https://doi.org/ 10.1175/1520-0442(1999)012<1990:TENOSD>2.0.CO;2.

Cai, W., P. van Rensch, T. Cowan, and H. H. Hendon, 2011: Teleconnection pathways of ENSO and the IOD and the mechanisms for impacts on Australian rainfall. J. Climate, 24, 3910-3923, https://doi.org/10.1175/2011JCLI4129.1.

Camargo, S. J., and A. H. Sobel, 2010: Revisiting the influence of the quasi-biennial oscillation on tropical cyclone activity. J. Climate, 23, 5810-5825, https://doi.org/10.1175/2010JCLI3575.1.

Cao, J., Z. Wen, Y. Chang, and X. Li, 2012: Wavelet analysis of the convectively-coupled equatorial waves. Sci. China Earth Sci., 55, 675-684, https://doi.org/10.1007/s11430-011-4298-7.

Chu, P.-S., and J.-B. Wang, 1997: Recent climate change in the tropical western Pacific and Indian Ocean regions as detected by outgoing longwave radiation records. J. Climate, $\mathbf{1 0}$, 636-646, https://doi.org/10.1175/1520-0442(1997)010<0636: RCCITT $>2.0 . \mathrm{CO} ; 2$.

Collimore, C. C., D. W. Martin, M. H. Hitchman, A. Huesmann, and D. E. Waliser, 2003: On the relationship between the QBO and tropical deep convection. J. Climate, 16, 2552-2568, https://doi.org/ 10.1175/1520-0442(2003)016<2552:OTRBTQ > 2.0.CO;2.

Comiso, J. C., W. N. Meier, and R. Gersten, 2017: Variability and trends in the Arctic Sea ice cover: Results from different techniques. J. Geophys. Res. Oceans, 122, 6883-6900, https:// doi.org/10.1002/2017JC012768.

Crooks, S. A., and L. J. Gray, 2005: Characterization of the 11-year solar signal using a multiple regression analysis of the ERA-40 dataset. J. Climate, 18, 996-1015, https://doi.org/10.1175/JCLI-3308.1.

Dee, D. P., and Coauthors, 2011: The ERA-Interim reanalysis: Configuration and performance of the data assimilation system. Quart. J. Roy. Meteor. Soc., 137, 553-597, https://doi.org/ 10.1002/qj.828.

Duvel, J.-P., and Coauthors, 2001: The ScaRaB-Resurs earth radiation budget dataset and first results. Bull. Amer. Meteor Soc., 82, 1397-1408, https://doi.org/10.1175/1520-0477(2001) 082<1397:TSRERB $>2.3$. CO;2.

Farge, M., 1992: Wavelet transforms and their applications to turbulence. Annu. Rev. Fluid Mech., 24, 395-457, https:// doi.org/10.1146/annurev.fl.24.010192.002143.

Gastineau, G., B. J. Soden, D. L. Jackson, and C. W. O'Dell, 2014: Satellite-based reconstruction of the tropical oceanic clear-sky outgoing longwave radiation and comparison with climate models. J. Climate, 27, 941-957, https://doi.org/10.1175/JCLID-13-00047.1.

Gray, L. J., and Coauthors, 2010: Solar influences on climate. Rev. Geophys., 48, RG4001, https://doi.org/10.1029/2009RG000282.

Gruber, A., and A. F. Krueger, 1984: The status of the NOAA outgoing longwave radiation data set. Bull. Amer. Meteor. Soc., 65, 958-962, https://doi.org/10.1175/1520-0477(1984) 065<0958:TSOTNO > 2.0.CO;2.

Gubbins, D., 2004: Time Series Analysis and Inverse Theory for Geophysicists. Cambridge University Press, 272 pp.

Hood, L., S. Schimanke, T. Spangehl, S. Bal, and U. Cubasch, 2013: The surface climate response to 11-yr solar forcing during northern winter: Observational analyses and comparisons with GCM simulations. J. Climate, 26, 7489-7506, https:// doi.org/10.1175/JCLI-D-12-00843.1.

Hu, Z.-Z., B. Huang, J. L. Kinter, Z. Wu, and A. Kumar, 2012: Connection of the stratospheric QBO with global atmospheric general circulation and tropical SST. Part II: Interdecadal variations. Climate Dyn., 38, 25-43, https://doi.org/10.1007/ s00382-011-1073-6.

Kiladis, G. N., J. Dias, K. H. Straub, M. C. Wheeler, S. N. Tulich, K. Kikuchi, K. M. Weickmann, and M. J. Ventrice, 2014: A comparison of OLR and circulation-based indices for tracking the MJO. Mon. Wea. Rev., 142, 1697-1715, https://doi.org/ 10.1175/MWR-D-13-00301.1.

Laken, B. A., and J. Čalogović, 2011: Solar irradiance, cosmic rays and cloudiness over daily timescales. Geophys. Res. Lett., 38, L24811, https://doi.org/10.1029/2011GL049764.

Liebmann, B., and C. A. Smith, 1996: Description of a complete (interpolated) outgoing longwave radiation dataset. Bull. Amer. Meteor. Soc., 77, 1275-1277.

Lim, E. S., U. Das, C. J. Pan, K. Abdullah, and C. J. Wong, 2013: Investigating variability of outgoing longwave radiation over peninsular Malaysia using wavelet transform. J. Climate, 26, 3415-3428, https://doi.org/10.1175/JCLI-D-12-00345.1.

Lucas, L. E., D. E. Waliser, P. Xie, J. E. Janowiak, and B. Liebmann, 2001: Estimating the satellite equatorial crossing time biases in the daily, global outgoing longwave radiation dataset. J. Climate, 14, 2583-2605, https://doi.org/10.1175/ 1520-0442(2001)014<2583:ETSECT>2.0.CO;2.

Ma, L. H., Y. B. Han, and Z. Q. Yin, 2010: Quasi-biennial oscillation signals in outgoing long-wave radiation of the equator. Adv. Space Res., 46, 1477-1481, https://doi.org/10.1016/ j.asr.2010.07.020.

Matthes, K., and Coauthors, 2017: Solar forcing for CMIP6 (v3.2). Geosci. Model Dev., 10, 2247-2302, https://doi.org/10.5194/ gmd-10-2247-2017.

Meehl, G. A., 1987: The annual cycle and interannual variability in the tropical Pacific and Indian Ocean regions. Mon. Wea. Rev., 115, 27-50, https://doi.org/10.1175/1520-0493(1987)115<0027: TACAIV $>2.0 . \mathrm{CO} ; 2$

- , and J. M. Arblaster, 2002: The tropospheric biennial oscillation and Asian-Australian monsoon rainfall. J. Climate, 15, 722-744, https://doi.org/10.1175/1520-0442(2002)015<0722: TTBOAA $>2.0 . \mathrm{CO} ; 2$

Mitchell, D. M., and Coauthors, 2015: Signatures of naturally induced variability in the atmosphere using multiple reanalysis datasets. Quart. J. Roy. Meteor. Soc., 141, 2011-2031, https:// doi.org/10.1002/qj.2492.

Newman, M., and Coauthors, 2016: The Pacific Decadal Oscillation, revisited. J. Climate, 29, 4399-4427, https://doi.org/ 10.1175/JCLI-D-15-0508.1. 
Nishimoto, E., and S. Yoden, 2017: Influence of the stratospheric quasi-biennial oscillation on the Madden-Julian oscillation during austral summer. J. Atmos. Sci., 74, 1105-1125, https:// doi.org/10.1175/JAS-D-16-0205.1.

Pascale, S., W. R. Boos, S. Bordoni, T. L. Delworth, S. B. Kapnick, H. Murakami, G. A. Vecchi, and W. Zhang, 2017: Weakening of the North American monsoon with global warming. Nat. Climate Change, 7, 806-812, https://doi.org/10.1038/nclimate3412.

Reynolds, R. W., T. M. Smith, C. Liu, D. B. Chelton, K. S. Casey, and M. G. Schlax, 2007: Daily high-resolution-blended analyses for sea surface temperature. J. Climate, 20, 5473-5496, https://doi.org/10.1175/2007JCLI1824.1.

Robock, A., 2000: Volcanic eruptions and climate. Rev. Geophys., 38, 191-219, https://doi.org/10.1029/1998RG000054.

Saji, N. H., and T. Yamagata, 2003: Possible impacts of Indian Ocean dipole mode events on global climate. Climate Res., 25 , 151-169, https://doi.org/10.3354/cr025151.

Sato, M., J. E. Hansen, M. P. McCormick, and J. B. Pollack, 1993: Stratospheric aerosol optical depths, 1850-1990. J. Geophys. Res., 98, 22 987-22 994, https://doi.org/10.1029/93JD02553.

Self, S., M. R. Rampino, J. Zhao, and M. G. Katz, 1997: Volcanic aerosol perturbations and strong El Niño events: No general correlation. Geophys. Res. Lett., 24, 1247-1250, https://doi.org/ 10.1029/97GL01127.

Son, S.-W., Y. Lim, C. Yoo, H. H. Hendon, and J. Kim, 2017: Stratospheric control of the Madden-Julian oscillation. J. Climate, 30, 1909-1922, https://doi.org/10.1175/JCLI-D-16-0620.1.

Taylor, P. C., and N. G. Loeb, 2013: Impact of sun-synchronous diurnal sampling on tropical TOA flux interannual variability and trends. J. Climate, 26, 2184-2191, https://doi.org/10.1175/ JCLI-D-12-00416.1.

Torrence, C., and G. P. Compo, 1998: A practical guide to wavelet analysis. Bull. Amer. Meteor. Soc., 79, 61-78, https://doi.org/ 10.1175/1520-0477(1998)079<0061:APGTWA > 2.0.CO;2.

— monsoon system. J. Climate, 12, 2679-2690, https://doi.org/ 10.1175/1520-0442(1999)012<2679:ICITEM > 2.0.CO;2.

Vera, C., and Coauthors, 2006: Toward a unified view of the American monsoon systems. J. Climate, 19, 4977-5000, https:// doi.org/10.1175/JCLI3896.1.

Vitorino, M. I., P. L. da Silva Dias, and N. J. Ferreira, 2006: Observational study of the seasonality of the submonthly and intraseasonal signal over the tropics. Meteor. Atmos. Phys., 93, 17-35, https://doi.org/10.1007/s00703-005-0162-7.
Waliser, D. E., and W. Zhou, 1997: Removing satellite equatorial crossing time biases from the OLR and HRC datasets. J. Climate, 10, 2125-2146, https://doi.org/10.1175/1520-0442(1997)010<2125: RSECTB $>2.0 . \mathrm{CO} ; 2$

Wallace, J. M., R. L. Panetta, and J. Estberg, 1993: Representation of the equatorial stratospheric quasi-biennial oscillation in EOF phase space. J. Atmos. Sci., 50, 1751-1762, https://doi.org/ 10.1175/1520-0469(1993)050<1751:ROTESQ > 2.0.CO;2.

Wang, C., R. H. Weisberg, and J. I. Virmani, 1999: Western Pacific interannual variability associated with the El Niño-Southern Oscillation. J. Geophys. Res., 104, 5131-5149, https://doi.org/ 10.1029/1998JC900090.

Weng, H., K. Ashok, S. K. Behera, S. A. Rao, and T. Yamagata, 2007: Impacts of recent El Niño Modoki on dry/wet conditions in the Pacific rim during boreal summer. Climate Dyn., 29, 113-129, https://doi.org/10.1007/s00382-007-0234-0.

Wheeler, M., and G. N. Kiladis, 1999: Convectively coupled equatorial waves: Analysis of clouds and temperature in the wavenumber-frequency domain. J. Atmos. Sci., 56, 374-399, https://doi.org/10.1175/1520-0469(1999)056<0374: $\mathrm{CCEWAO}>2.0 . \mathrm{CO} ; 2$.

_ , and H. H. Hendon, 2004: An all-season real-time multivariate MJO index: Development of an index for monitoring and prediction. Mon. Wea. Rev., 132, 1917-1932, https://doi.org/ 10.1175/1520-0493(2004)132<1917:AARMMI>2.0.CO;2.

Wilks, D. S., 2011: Statistical Methods in the Atmospheric Sciences. 3rd ed. International Geophysics Series, Vol. 100, Academic Press, $676 \mathrm{pp}$.

Wu, R., and B. P. Kirtman, 2004: The tropospheric biennial oscillation of the monsoon-ENSO system in an interactive ensemble coupled GCM. J. Climate, 17, 1623-1640, https://doi.org/10.1175/ 1520-0442(2004)017<1623:TTBOOT>2.0.CO;2.

Xiao, Z., Y. Liao, and C. Li, 2016: Possible impact of solar activity on the convection dipole over the tropical Pacific Ocean. J. Atmos. Sol. Phy., 140, 94-107, https://doi.org/10.1016/ j.jastp.2016.02.008.

Yim, S.-Y., B. Wang, J. Liu, and Z. Wu, 2014: A comparison of regional monsoon variability using monsoon indices. Climate Dyn., 43, 1423-1437, https://doi.org/10.1007/s00382013-1956-9.

Yoo, C., and S.-W. Son, 2016: Modulation of the boreal wintertime Madden-Julian oscillation by the stratospheric quasi-biennial oscillation. Geophys. Res. Lett., 43, 1392-1398, https://doi.org/ 10.1002/2016GL067762. 